\title{
A Psychosocial Perspective about Mental Health and League of Legends in Brazil
}

\author{
Luiz Paulo Carvalho (Did [ Universidade Federal do Rio de Janeiro | luiz.paulo.carvalho@ppgi.ufrj.br ] \\ José Antonio Suzano [D [ Universidade Federal do Rio de Janeiro | jose.suzano@matematica.ufrj.br ] \\ Ingrid Gonçalvez [ Pontifícia Universidade Católica do Rio de Janeiro | ingridtfaria@gmail.com ] \\ Silas Pereira Filho [ [ Universidade Federal do Rio de Janeiro | silaslfilho@gmail.com ] \\ Flávia Maria Santoro (D [ Universidade do Estado do Rio de Janeiro | flavia@ime.uerj.br ] \\ Jonice Oliveira (iD [ Universidade Federal do Rio de Janeiro | jonice@ dcc.ufrj.br ]
}

\begin{abstract}
Every month, millions of users worldwide play the online digital game League of Legends, which also contains a server dedicated to the Brazilian region. Social oppression by race, skin color, sexual orientation, among others, occurs within the game and is reported constantly. In this paper, we analyzed possible indications of depressive disorder by using an online questionnaire as a basis. We used quantitative and qualitative methods, analyzing the relationship between the interactions and the social identities of the players. We define quantitative hypotheses and qualitative syntheses related to different social factors of the game through the analysis of 604 responses. League of Legends has a negative influence on the mental health of socially peripheral players, and the qualitative analysis exposes specific and widespread cases of oppression and discrimination. We present a discussion on ethics, possible collusion with oppression, and proposals for mitigation or solution.
\end{abstract}

Keywords: League of Legends, Mental Health, Psychometrics, Social Oppression, Ethics

\section{Introduction}

League of Legends (LoL) is an online digital game of the genre MOBA (Massive Online Battle Arena) developed and published by the company Riot Games, USA based. ${ }^{1}$ Riot Games last published official figures related to its player base in 2016, and during the decade-long anniversary event, in 2019, they informally exposed the number of eight million simultaneous players around the world (Goslin, 2019). Several media vehicles estimate values for the number of active players monthly in the game, ranging from eighty and one hundred million players (Marchetti, 2017). In a conservative estimate, LoL has more monthly players than the number of citizens in France, the twentieth country with the largest population in the world, with sixty-seven million people. $^{2}$

There is a server dedicated to Brazil (named as region), the BR server. ${ }^{1}$ There is no official communication record of Riot Games showing data related to BR server players, only estimates or informal speculations are found. Players are randomly matched with other unknown ones, and they interact as allies, or opponents, to achieve the game's objective. Players' expectations include entertainment, competition, and fun, but not social oppression.

LoL is a game full of toxic social interactions and oppressions among its players, such as LGBTphobia, racism, machismo, xenophobia, and others (Carvalho et al., 2018; Almeida et al., 2019; Flores and Real, 2018). Social toxicity is not a behavior unique to the Brazilian scenario. Behaviors, such as flaming and cussing, are also widely perceived on U.S. and European servers (Denzer, 2020).
Virtual social interactions are not detached from the socio-material reality perceived by the players involved with the game because we are biopsychosocial creatures. Thus, these interactions affect people, varying in degree and extent, and even those who are exclusively spectators (Bogost, 2007). LoL toxic and degraded social atmosphere motivated us to our goal of measuring and understanding how social oppression influences the mental health of players, specifically the depression (Del Porto, 1999), based on the attributes of their identity: gender, sexual orientation, skin color and region where they live.

We seek to analyze the several hypotheses listed in Section 3, focusing on the identity and mental health of respondents from a quantitative, qualitative, and psychometric approach (Hutz et al., 2015), based on a questionnaire published on Online Social Networks (OSN), which received hundreds of responses. Quantitatively, considered the oppression, can depressive disorders be traced to its players by social influence regarding LoL experiences? Qualitatively, how are direct and indirect factors perceived?

Focusing on depressive disorders, the psychometric artifact selected to measure the influence on mental health was the Center for Epidemiological Scale - Depression (CES-D) (Radlof, 1977), adapted to the specific context of this research. This study does not intend to diagnose depressive disorders based on its psychometric results. Social interaction in LoL is one of the elements that make up the experiences of its players and their respective mental health. It is not possible to objectively state that LoL is a determining factor for consolidating depressive disorders in

\footnotetext{
${ }^{1}$ https://en.wikipedia.org/wiki/League_of_Legends. Accessed: 01 January 2021

${ }^{2} \mathrm{https} / / /$ www.cia.gov/library/publications/the-world-factbook/. Accessed: 01 January 2021
} 
its players only through their social identities and the multifaceted complexity of the reality they experience, but there is a dialogical and environmental psychic communication relationship (Wei et al., 2012; Stetina et al., 2011). We intend to identify associations between social identities and depressive disorders in a quantitative statistical way and qualitative interpretive way. There are no other works that collectively garner so much participation, the plurality of approaches, completeness of coverage, and analysis of LoL social interactions in the Brazilian context, to the best of our knowledge.

In Carvalho et al. (2018), we detail how social interaction takes place within the LoL interface. Wikipedia page ${ }^{1}$ and the LoL website ${ }^{3}$ present what is needed regarding the gameplay, dynamics, and mechanics.

This work is structured as follows: Section 2 presents the theoretical foundation; Section 3, methodology, method, and hypotheses of the research; Section 4, quantitative survey results; Section 5, qualitative survey results; Section 6, further discussion; Section 7, conclusion.

\section{Theoretical Foundations}

This Section presents the concepts that guide this paper.

\subsection{Prejudice, Discrimination and Oppression}

David and Derthick (2017) and Benuto et al. (2020) provide the conceptual bases of this Section. The terms covered here are not consensual in the State of the Art, but we adopt them from these authors.

"Prejudice refers to the attitudes, feelings, or affective components of our perceptions about members of certain social groups. The emotions or affect we attach to certain groups may be positive or negative and may be conscious or nonconscious" (David and Derthick, 2017). Prejudices are natural internalized psychosocial phenomena, not always rationalized. They are associated with individual, or collective, values, and when considering contextual power and privilege relationships, neutrality is impossible.

"Discrimination is the behavior that results from a person's stereotypes and prejudices. In other words, when one's actions are driven by biased beliefs and attitudes against a certain group of people, then one is discriminating against that particular group" (David and Derthick, 2017).

Discrimination is an externalized, rationalized social phenomenon. It is reflected on concrete actions, even if symbolic interaction, based on prejudices or mental models, known as formed concepts or constructs. Like prejudice, neutrality is impossible in the practice of discrimination. While prejudice can be reduced in operation at the level of the senses, in the unconscious, or subconscious, discrimination necessarily operates at the level of perception, associating meanings with structured contexts. That is, discrimination is rational. A certain set of mental associations encourages one person to discriminate against another in a particular context. For example, there is no skin color discrimination in a community context entirely composed of people with a specific skin color, in which everyone is explicitly identified as such. Although other discriminations are possible, color discrimination is incompatible with that community.

The discrimination addressed in this work is social. The discriminating act is based on principles, values, and traditions not categorically intrinsic to the "social" aspect. For example, suppose that as a LoL match progresses, a specific player in the support position decides to dedicate their attention and functional potential to a female teammate: (i) this may be a discriminatory strategical decision seeking their team victory, balancing their skills unevenly; or (ii) this may be a discriminatory social decision, underestimating the female player who, even though might be the strongest and offers the highest chance of victory if assisted, is perceived as a woman and, by this player, as "inferior"; or (iii) the two previous options, however (ii) is unconscious.

Linked to prejudice and discrimination, and the focus of this work, there is social oppression. Oppression is "the act of imposing on [...] others [...] a label, role experience, or set of living conditions that is unwanted, needlessly painful, and detracts from physical or psychological well-being [...] (such as) demeaning hard labor, degrading job roles, ridicule, and negative media images and messages that foster and maintain distorted beliefs" (Hanna et al., 2000).

David and Derthick (2017) ostensibly detail other characteristics, definitions, and specificities of oppression. Oppression has two components: power and privilege. The act is rational, conscious, deliberate, and objective, but the phenomenon is complex and multifaceted. For example, individuals from specific social groups have difficulty identifying or feeling empathy related to oppression directed at other social groups, e.g., confusing oppression with "humor" or being confused about the nuances of speech.

As we will see in Section 5, which is related to the qualitative analysis, when a player says: "a woman's place is in the kitchen", "you are black, dirty monkey", or "gays deserve death", there is a discursive limitation related to any subjectivity. There is no intention other than social oppression. It is also pertinent to stress the term violence. In discursive practice, violence and oppression are conceptually close terms. Therefore, we will consider violence as a critical stage in the effectiveness of the oppression phenomenon. For example, as one of the testimonies collected, there is oppression when a male player threatens a female player with rape. It configures symbolic violence that can result in a physiological socio-material impact, such as crying, loss of sleep or appetite, or even recalling traumatic experiences memories.

Prejudice and discrimination cross between social groups. Considering oppression as based on power and privilege through a hierarchy, pseudo-phenomena such as "reverse racism" or "misandry" is inconceivable in the social matrix.

\footnotetext{
${ }^{3}$ https://leagueoflegends.com/en-us/. Accessed: 01 January 2021
} 


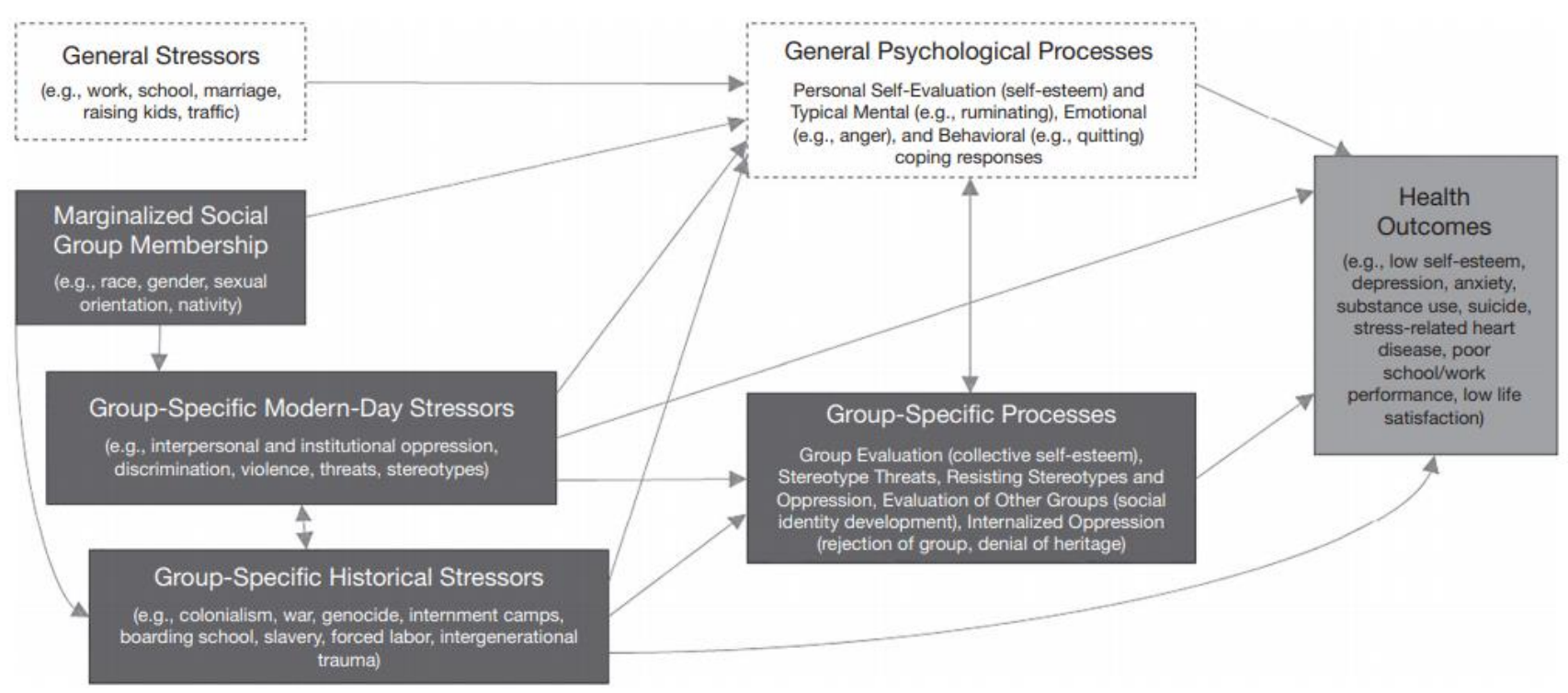

Figure 1: The potential consequences of oppression on marginalized peoples (David and Derthick, 2017)

Discrimination against a white person as "sour milk" does not promote tension or alteration of power or privilege. This white person may selfishly and imaginary feel "socially oppressed", but this is an invalid categorization. Despite not setting up a scenario of social oppression, other phenomena are plausible, such as feeling offended. Often, people in advantageous positions of power or privilege do not recognize or perceive their social conditions, holistically alienated from the social context in which they participate or are inserted. Their collective and empathic conscience is passively oppressive by disregarding other social groups in a situation of inferior power and privilege and bringing the protagonism of the oppression phenomena to themselves.

Figure 1 shows an associative model between historical or contemporary oppression and its consequences on the life and well-being of marginalized groups.

\subsection{Depressive Disorders and Psychometrics}

Virtual social interactions that are unpleasant or loaded with negative effects culminate in mental pathologies, such as depressive disorder (Hutz et al., 2015). Depression, as a symptom, is part of the clinical notion of Post-Traumatic Stress Disorder, given the diagnoses referring to the Diagnostic and Statistical Manual of Mental Disorders (DSM-5); as a syndrome, it presents alteration of sleep, mood, appetite; insensitivity to pleasure; apathy; melancholy (APA, 2014)

Identifying symptoms is essential to reach depressive people or someone indicating some potential to develop the pathology (Hutz et al., 2015). The challenge, in this paper, is to measure depressive symptoms or behaviors associated with LoL players and their social identities. The CES-D questionnaire is presented as a solution found and recommended in the literature (Jonhson, 2015), used in several studies.

DeChoudhury et al. (2013) use CES-D to measure depression levels in Facebook users, correlating the score with other variables, e.g., language patterns and behavior within the platform. For over 32 years, Rosenquist et al.
(2011) use CES-D to explore and identify nuances of depression through the personal data of users on social networks, such as scattering and influence factors among members.

The measurement based on epidemiological studies of population depressive symptomatology can be performed through the CES-D scale (Jonhson, 2015). It differs from the other scales for clinical diagnostics situations and the disease's severity evaluation throughout treatment (Radlof, 1977). It is an example of psychological psychometric testing, highly consistent and approved in test-retest. As a psychology field, psychometrics uses measuring instruments to quantify specific human aspects, being useful when comparing the effectiveness of interventions among professionals (Del Porto, 1999).

\subsection{Social Oppression inside League of Legends}

Social toxicity in LoL is the main object of analysis of several Brazilian studies (Carvalho et al., 2018; Almeida et al., 2019; Flores and Real, 2018; Ratan et al., 2015; Araújo, 2019; Carvalho and Rocha, 2018; Medrado and Mendes, 2020). It is relevant to contextualize how certain specific social interactions of this system occur. As related in the studies above, the four types of social discrimination most perceived and recorded in player communications are:

- Gender. Specifically, when gender aspects are used as objects of offense. It is not restricted to the female sex, as men are also victims of arguments such as, e.g., "playing like little girls".

- Race/skin color. Although no element objectively shows the player's skin color, there are offenses associated with this aspect, in the connotative expectation of offending the race/skin color associating it with negative elements.

- Sex life/LGBTphobia. Depending on the position in the game or the champion (character), a player can be read and labeled as LGBT+, e.g., for occupying a supportive position. 
- Region of origin/xenophobia. Occurrences perceived as offense or injury are often associated with the Midwest, North, and Northeast regions of Brazil and their sociocultural characteristics.

\subsection{Communication inside League of Legends}

Concerning means of communication, two manners are available: by voice and by text. Çakir's (2020) text provides a comprehensive technical explanation related to communication and muting.

Text communication is a feature implemented since the game's release. The player can communicate by text with his friends: from their friends' list, in the lobby with his allies, in the match, and on the post-match screen with all the other players. Voice communication was launched in 2018. It is relatively recent compared to text and also less used. Unlike text, a player can disable voice communication entirely.

The game offers the functionality of muting other players. Communication of muted players is not exposed to those who muted them. LoL recommends silencing a toxic player as soon as a negative interaction occurs. ${ }^{4}$ The controversy arises from the point that the player asks themself: "if I'm being targeted, why do I need to punish myself by taking action, like muting, and the toxic player gets away with it?". It seems like a values reversal, a moral recoil. The victim is then punished multiple times: for being offended or oppressed; being obliged to mute the oppressor; not ensuring the end of toxicity. It gives victims the perception that they are being subtracted from one aspect of their communication in the game, but the aggressor, in turn, does not (Carvalho et al., 2018).

After experiencing a situation of oppression, the victim then assumes that $a$ priori these acts will happen again in future matches (Almeida et al., 2019; Flores and Real, 2018), and as a result, they will silence everyone at the beginning of the match, whether opponents or allies. This act is not only problematic due to the negative expectation of digital games but also impairs player communication with the team. Consciously or unconsciously, the player gives up communication and, even if it helps achieve victory, preemptively avoids possible toxic social interactions. The player restrains themself while oppressors remain freely expressing themselves. At last, they perceive the experiences and social experiences they choose not to live, aiming to avoid oppression through silencing and feeling detached, distressed that they could be building friendships and positive connections.

As Schulman (2016) points out: "The traumatized person's sense of their ability to protect themselves has been damaged or destroyed. They feel endangered, even if there is no actual danger in the present because in the past, they have experienced profoundly invasive cruelty and they know it is possible." (Schulman, 2016). The negative effect subjectivity of social oppression is inherent to the individual who experienced, directly as a victim or indirectly as a spectator, the episode. When considering the expectation involving an online digital game, dissociated from the experience of oppression, added to all the external factors, it is perceived as understandable that the parties respond to these episodes by thinking they do not happen again. This way, a positive functionality, which contributes to victory, is given up, in exchange for preventing potential negative interactions and oppression.

In this sense, the mechanisms to deal with socially toxic situations made available by the game are more harmful to the victim's psyche but not to the oppressor.

The game features mechanisms for players to report for verification situations they find wrong or uncomfortable, such as oppression. Many community members do not see these mechanisms as effective (Carvalho et al., 2018). If the player receives the maximum penalty, permanent ban from their account, they can still create another account and continue playing on the same day. Although they argue that this is a valid solution, ${ }^{4}$ there is no guarantee that this oppressive player will return to the game and stop negative attitudes with other players or, in the worst-case scenario possible (with incredibly low probability), not be matched with the same players who reported they, repeating the same oppression(s).

Considering the case of female players and how the socio-technical aspects are currently in place, there is a propensity for silencing instead of guaranteeing voice, even if its numerical quantity grows (Medrado and Mendes, 2020). Voice, in this sense, goes beyond traditional communication. Any expression of elements perceived as the feminine is at risk of oppressive side effects.

\section{Research method and methodology}

We applied the questionnaire methodology specifically designed to the health fundamentals and context (Jonhson, 2015) to analyze the hypotheses, build the adapted CESD form (Radlof, 1977) and collect relevant data.

After analyzing the social scenario of oppression in the game context, the research followed these steps: 1 . Survey of hypotheses; 2 . Preparation of the questionnaire, adapting the questions of the CES-D; 3. Publicization and dissemination; 4. Structuring, treatment, and standardization of collected data; 5. Statistical analysis of the data; 6. Evaluation and validation of hypotheses based on the data analyzed; 7 . Qualitative or mixed analysis of discursive responses; 8. Consolidation of discussion and contributions.

\subsection{Identity categorization}

Based on the recurrent categories of oppression, we aim to collect the following data: gender, skin color, sexual orientation, and geographic region of origin. This data builds the respondent's identity.

\footnotetext{
${ }^{4}$ https://lol.garena.com/news/general--how-handle-negative-players-mute-report-and-stay-positive. Accessed: 01 January 2021
} 


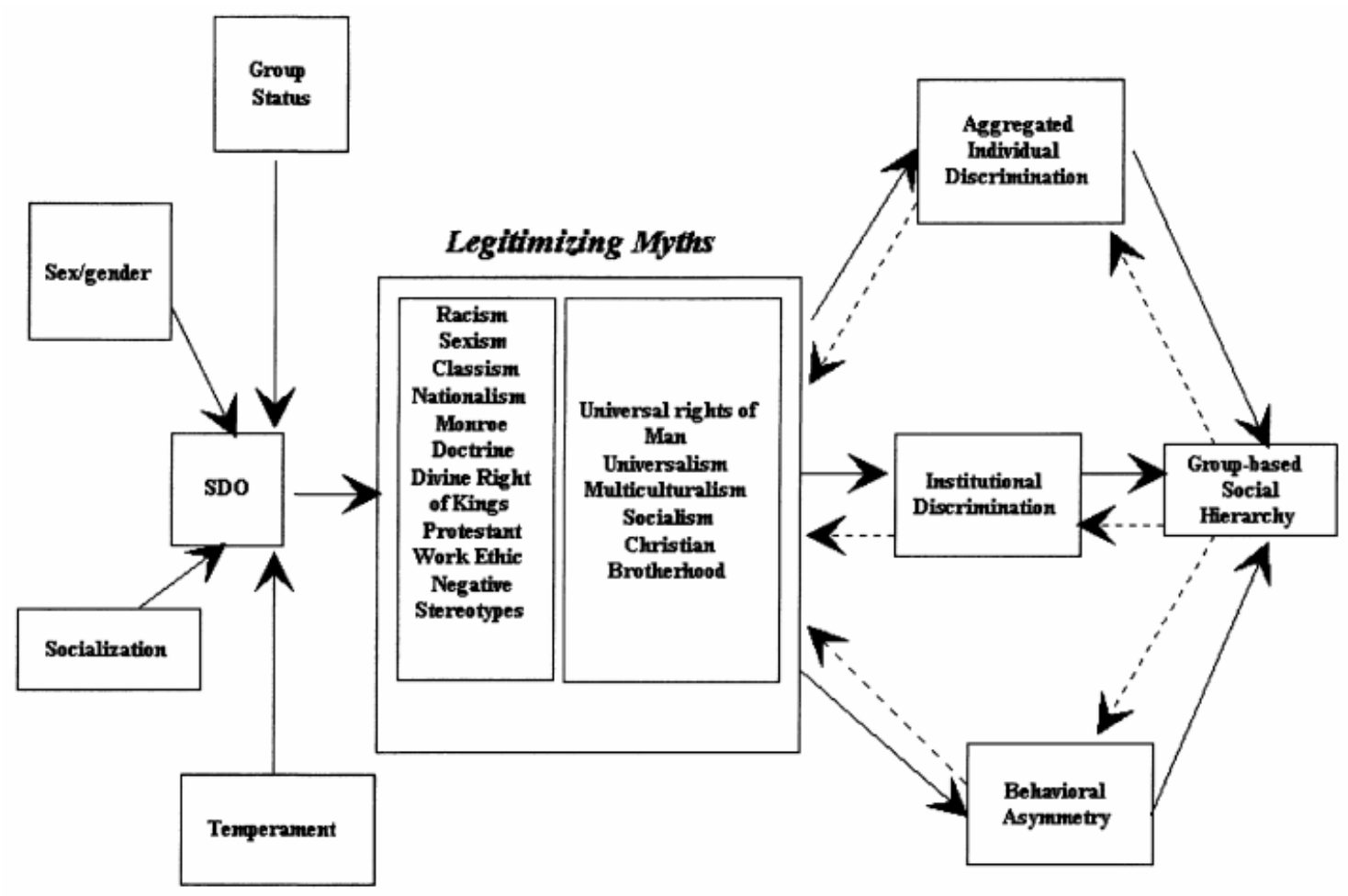

Figure 2: SDT schematic (Sidanius and Pratto, 1999)

We used Sidanius and Pratto's (1999) Social Dominance Theory (SDT), in which the social identity of a better position in the social hierarchy is occupied by a player who identifies as male, white skin color, heterosexual sexual orientation, and coming from the South or Southeast regions. Any deviant attribute characterizes it as socially peripheral, potentially a target of oppression, even as a spectator, capable of feeling it directly or indirectly. Figure 2 graphically presents the SDT scheme.

Two categories are perceived: individual and groupbased hierarchies. Five categories of identity are established in this research, and each identity is a group. Id.4 is the identity that adds all the dominant social attributes. The social group of peripherals is composed of id.3, id.2, id.1, and id.0.

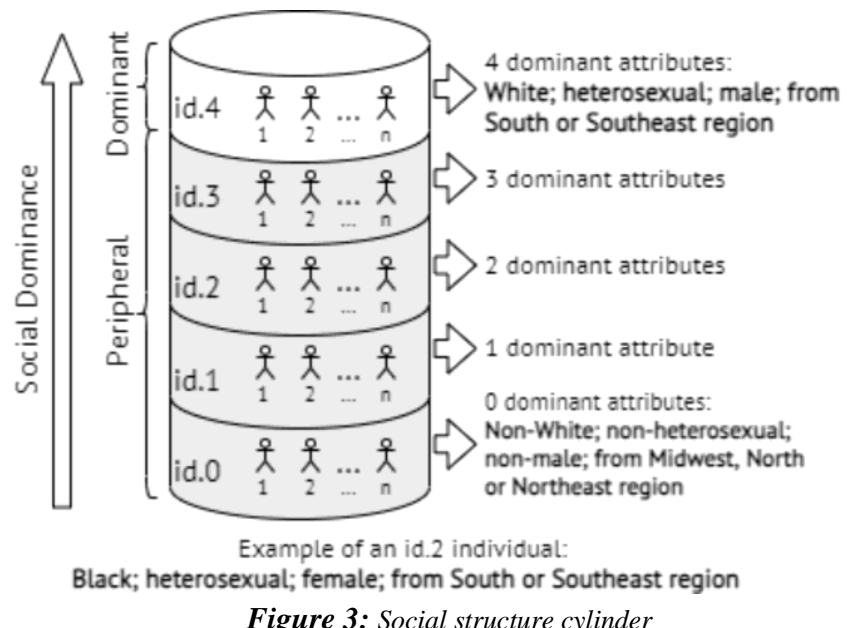

Like a cylinder of five overlapping floors, illustrated by Figure 3, id.4 is at the top and the rest neatly below. id.0 corresponds to the most peripheral social position in the hierarchy. An individual whose sum of attributes adds up to 4 , the maximum, is grouped in id.4 and so respectively to the other identities.

For instance, a player who identifies himself as a man, black, heterosexual, and from the northern region is categorized as id.2 and grouped with the others of the same category. Oppression of skin color or origin region will be more likely to affect their mental health.

Oppression does not occur top-down. It cuts across individuals and groups. Although id.4 is not responsible for all the oppression present in the game, its position of social power and privilege immunizes it from socio-material consequences external to the game, considering the Brazilian macro-context. An id.4 individual can still perceive oppression, be touched, be moved, and cry. The subjective reaction is individual, disconnected from the structural relationship of contemporary society as a whole. For example, during a match, the phrase "you are a horrible man, and you are a shit who will never get a job" is addressed to a male player. This interaction can start subjectively an intense emotional multi-causal process that results in sadness and crying. However, this does not mean objectively that men are harmed in terms of power or privilege to access the majority and the best jobs.

Player A can perceive Player B's data within the game in two ways: (i) if $\mathrm{B}$ announces it, without an effective guarantee that $\mathrm{B}$ is being sincere; (ii) if $\mathrm{A}$ deduces it, for example: if Player B's nickname is "Maria", then player B is a woman. Since discrimination is independent of groups' hierarchies, complexity is increased: a woman can oppress another woman without either of them knowing that they are, in fact, women. What would be a materially invalid phenomenon is viable due to the game anonymity. Anonymity, per se, is not causally related to the problem. 
Suppose a women's volleyball match. It is unlikely that one player will underestimate the technical quality of the other, discriminating against her just for "being a woman".

\subsection{Quantitative and qualitative analysis}

Table 1 presents the hypotheses of this research, based on the phenomena in (Carvalho et al., 2018; Almeida et al., 2019; Flores and Real, 2018; Ratan et al., 2015; Araújo, 2019; Carvalho and Rocha, 2018; Medrado and Mendes, 2020). The hypotheses are statistically analyzed through quantitative approaches, as detailed in Section 4. Section 5 presents the synthesis by the qualitative approach of the discursive and open responses. Quantitative analyses are used as support when appropriate, configuring it a mixed approach.

Table 1: Research hypotheses, based on CES-D and their identities

\begin{tabular}{|l|l|}
\hline H. 1 & Dominants have lower scores compared to peripherals. \\
\hline H. 1.1 & Males have lower scores compared to non-males. \\
\hline H. 1.2 & $\begin{array}{l}\text { Heterosexuals have a lower score compared to non- } \\
\text { heterosexuals. }\end{array}$ \\
\hline H. 1.3 & White has lower scores when compared to non-whites. \\
\hline H. 1.4 & $\begin{array}{l}\text { South and Southeast regions have a lower } \\
\text { score compared to the Midwest, North, and Northeast } \\
\text { regions. }\end{array}$ \\
\hline H. 2 & $\begin{array}{l}\text { Playing time increases the score } \\
\text { of peripherals compared to dominants. }\end{array}$ \\
\hline H. 3 & $\begin{array}{l}\text { Muting increases the peripheral scores compared to } \\
\text { dominants. }\end{array}$ \\
\hline H. $\mathbf{4}$ & $\begin{array}{l}\text { The perception of oppression increases } \\
\text { the peripheral scores when compared to dominants. }\end{array}$ \\
\hline
\end{tabular}

\subsection{Questionnaire and adapted CES-D}

The online questionnaire method collected the data through the Google Forms system. All identity issues accompany the option "I prefer not to declare" and "Others". The questionnaire begins with the Free and Informed Consent Form and its details, respecting the principles of ethical scientific research (Diener and Crandall, 1978). Relevant survey data is available online ${ }^{5}$ and partially presented here.

The following personal data were collected for evaluation of $\mathrm{H} 1$ and its related data: (i) First and last name, anonymized regarding data protection; (ii) Biological sex, as we chose not to use the construct "gender" aiming at simplicity and objectivity, respecting the respondents' freedom of self-identification; (iii) Skin color, as we chose not to use "race" construct for the cultural complexity that this interpretation could generate; (iv) Sexual orientation, with a plural list of options in addition to "Heterosexual" and "Homosexual"; (v) State, specifically the region from which the respondent comes from; (vi) Summoner name, omitted regarding data protection.

We understand that these constructs are not restricted to those listed by us. We inserted the option "Others" so that respondents express freely and spontaneously according to their self-identification subjectivity (Butler, 2004).
For H2, H3, H4 were collected: (vii) Playing time, which we consider respondents that have already experienced the game and how much they play/have played; (viii) Muting, how respondents maintain communication in the game; (ix) Perception of oppression, if the respondent perceived oppression and how it occurred; (x) Type of oppression, within a predefined list of oppression types, the respondent could select how many and which ones he perceived.

We used the psychometric approach to measure the specific influence of the game, focusing on depressive disorders in the players, based on the CES-D (Radlof, 1977). The CES-D was adapted to the game context to contextualize and conduct the respondent to the measured validity of the phenomenon (Jonhson, 2015). The original form has twenty questions, ranging in four options and each with a specific weight, from 0 to 3: 0, "seldom or rarely"; 1, "once or a few times"; 2, "several times"; 3, "very often". We did not delimit time, willing to make the feedback more flexible and equate the measurement as it is only an aspect of the respondents' reality. Examples of adapted questions are: "My sleep was restless" to "The game affected my sleep"; "Willingness to cry" to "Willingness to cry because of what I witnessed in the game". This adapted questionnaire can be reused, considering the contextual and conceptual transferability requirements.

Considering the conceptual association, alias the twenty questions of the original CES-D, just seventeen were imported and adapted, using the same score. While traditional CES-D ranges from zero to sixty points $(4 \times 20)$, this adapted CES-D ranges from zero to fifty-two points (4 $\times 17)$.

The qualitative analysis is indirectly related to the hypotheses, complementing the research by entering the path of "how" the phenomenon occurs. Types and categories are extracted and analyzed, while specific and unique testimonies can be surgically scrutinized. The qualitative questions are (i) "Does the number of hours played per day change depending on something?"; (ii) "Was I (or others said I was) toxic, negative?"; (iii) "Freely, how do you feel about social interactions in League of Legends? How would you describe them?"; (iv) "If you could send one, and only one, suggestion for improvement to the game team that would be immediately obeyed, which would it be?"; (v) "If you have suffered or observed a case of oppression or social discrimination in League of Legends, can you report it here? If reliving the memory of the event is unhealthy, you can answer "I prefer not to report",

\subsection{Publicization and dissemination}

The questionnaire was published and made available between 06/04/2019 and 17/04/2019, using the Online Social Network Facebook as a medium of dissemination. We selected groups dedicated specifically to LoL to get participants. The three most relevant had approximately twenty-five thousand, eighty thousand, and two hundred thousand members. During the call for participation, they

${ }^{5} \mathrm{https} / / /$ drive.google.com/file/d/1g5XWeQBUjg5PFyIqDf7SB7wPUkmvENRH/view?usp=sharing. The original form was written in Brazilian Portuguese. Accessed: 01 January 2021 
were also asked to indicate acquaintances and share the questionnaire in a snowball style (Jonhson, 2015).

\subsection{Data processing and normalization}

The data was structured and organized in a table, followed by the treatment and normalization (Gideon, 2012). The records of respondents who did not consent to use their answers for research were discarded and normalized as "Other" entries. ${ }^{6}$ All fields left empty or inseparable from other options listed have been invalidated and normalized to "I prefer not to declare".

The four main attributes were replaced by either 0 or 1 to construct the identities. If the answer was "Male", "White", "Heterosexual", or some State of the Southeast or South region, the value was converted to 1 ; any other, 0 . If the respondent's answers add up to four points, their identity is socially dominant; if it varies between zero and three, from the most to least peripheral, its identity is socially peripheral.

CES-D responses were converted to equivalent numerical values. Questions seven, eleven, and fourteen were inversely proportional in value, i.e., the values are inverted in the opposite direction.

\subsection{Statistical and hypothesis analysis}

Arithmetic and statistical techniques were used for data inference (Agresti et al., 2017), such as sums, chained percentages, means, distribution functions, and graphs. They were all elaborated for a multidimensional visualization of the data.

Data are fully exposed and considered as collected and treated, statistically significant or not (Wasserstein et al., 2019). In this work, this topic involves socially peripheral and marginalized identities and a reality fraction in the context of digital games. For example, women are already socio-culturally estranged from this universe (Fox and Tang, 2014). On one of the few occasions Riot Games exposed player-related data in 2012, it accounted for more than $90 \%$ of its players as men (IGN, 2012). This portion of the population has a low possibility of achieving statistical significance compared to the whole (Agresti et al., 2017), but it cannot be neglected or forgotten (Wasserstein et al., 2019).

The sample population that scored 0 in the identity sum was disregarded as they totaled only 3 of the 607 respondents $(0.49 \%)$. The best approach to deal with this group is qualitative and in-depth due to its specificity (Jonhson, 2015). The homogeneity of statistical analyses tends to proportional consistency related to the number of samples of the population (Agresti et al., 2017), i.e., id.1 contains 62 individuals ( $\cong 10 \%$ of the total population). This small value results in a higher variance of statistical results but still valid.

\subsection{Qualitative, mixed, and in-depth analysis}

Hypotheses lead us to an objective perception of reality, framed in the boundaries that data and reach allowed (Recker, 2013). From this point on, we intend to examine the multiple realities and plural interpretations that discursive, open, or complementary questions can offer to the research, even quantitative. (Gideon, 2012; Bhattacherjee, 2012; Merriam and Tisdell, 2015; Locke, 2019).

At this stage, the intention is to deepen the analysis of the phenomenon. Based on screening, coding, and categorization we build a systematic structured analysis, which can enrich the quantitative assessment or present other views. This analysis can enrich the quantitative assessment and present other views.

\subsection{Summary of contributions and findings}

The synthesis of both quantitative and qualitative results will be presented in a separate Discussion section. Then, we will present the correlated research contributions and findings. The details of the qualitative analysis procedure can be found at the beginning of Section 5 .

\section{Quantitative results}

In this Section, we present the quantitative results and data related to the respective hypotheses, which will be discussed and deepened in Section 6. We traditionally rounded the CES-D calculations to integers. The database containing the questionnaire answers is available online for reproducibility, replication, and verification. ${ }^{7}$

Table 7 summarizes data associated with $\mathrm{H} 2, \mathrm{H} 3$, and $\mathrm{H} 4$, aiming for a better quantitative perception of the phenomena, considering the proportion of data compared to its identity population and the general population. Inconsistent, numerical, and comparatively abnormal data is configured in bold and italics.

We instrumentalize mathematical notation $\overline{\mathrm{CES}-\mathrm{D}}$ to express the operation of the specific mean CES-D. That is, the id.1 $\overline{\mathrm{CES}-\mathrm{D}}$ is the mean CES-D of all individuals grouped as id.1. We identify socially dominant, id.4, as "dominant"; and socially peripheral, id.3, id.2, id.1, as "peripheral".

\subsection{Overall results}

After data treatment and normalization, 604 valid records were achieved through the answers.

Table 2 presents the overall results. All groups that compose "peripheral" were included in it. A participant who identified as "Female", "White", "Bisexual", and "MG" scored 2, being part of this specific group that composes peripheral identities, id.2. Table 3 highlights results by identity, peripheral and dominant attributes.

\footnotetext{
${ }^{6}$ The Brazilian context is the essence of this research, in Brazilian Portuguese. In this way, we value the fidelity of data and speech or discourse phenomena without answers translations. In the specific need associated with the primary scope of the research, the respective free translation into English will be provided.

${ }^{7}$ https://docs.google.com/spreadsheets/d/e/2PACX-1vRVbpjKx52d_1D6HfgpXVFCDtm2ysrAhpkX_fKmACh87oyc-pAYSYnGLUPy-tAmwg/pubhtml. Accessed: 01 January 2021. To preserve research fidelity, the answers are in Brazilian Portuguese.
} 
Table 2: Overall results

\begin{tabular}{||c|c|c|c||c|c|c||}
\cline { 2 - 7 } \multicolumn{1}{l|}{} & All & Dom. & Per. & id. 3 & id. 2 & id. 1 \\
\hline \hline Qty. & 604 & 164 & 440 & 214 & 164 & 62 \\
\hline Qty. \% & 100 & 27.2 & 72.8 & 35.4 & 27.1 & 10.2 \\
\cline { 1 - 5 }$\overline{\text { CES-D }}$ & 16 & 15 & 17 & 16 & 17 & 19 \\
\hline $\begin{array}{l}\text { Above general } \\
\text { CES-D (16) \% }\end{array}$ & 49.0 & 43.3 & 51.1 & 45.3 & 52.4 & 67.7 \\
\hline \begin{tabular}{l} 
Below general \\
\hline CES-D (16) \%
\end{tabular} & 51.0 & 56.7 & 48.9 & 54.7 & 47.6 & 32.3 \\
\hline Highest CES-D & 44 & 38 & 44 & 44 & 42 & 37 \\
\hline Smallest CES-D & 3 & 4 & 3 & 5 & 3 & 5 \\
\hline \hline
\end{tabular}

Table 3: Detached results by identity

\begin{tabular}{|c|c|c|c|}
\hline & Qty. & Qty. \% & $C E S-D$ \\
\hline Male & 513 & 84.93 & 16 \\
\hline Non-male & 91 & 15.07 & 19 \\
\hline Heterosexual & 389 & 64.40 & 16 \\
\hline Non-heterosexual & 215 & 35.60 & 18 \\
\hline White & 358 & 59.27 & 16 \\
\hline Non-White & 246 & 40.73 & 17 \\
\hline South/Southeast & 428 & 70.86 & 17 \\
\hline Other regions & 177 & 29.14 & 16 \\
\hline
\end{tabular}

Table 4 shows a comparison between the $\overline{\mathrm{CES}-\mathrm{D}}$ and the proportion of individuals of a given identity category above and below it. The higher the above value, the worse; the higher the value below, the better. For example, $53.07 \%$ of the 348 white respondents scored $\overline{\mathrm{CES}-\mathrm{D}}$ lower than the overall population (16), indicating that more than half of this group has better results.

Table 4: Proportional results by identity, population comparison

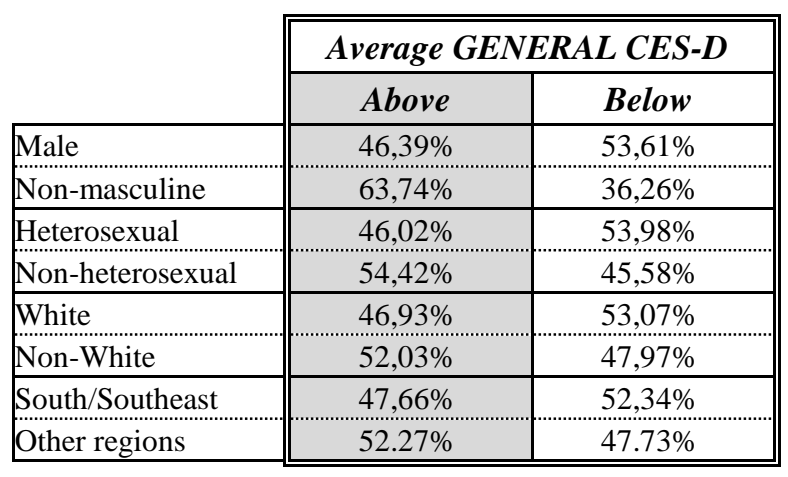

\subsection{Playing time}

The columns A, B, C, D, E, and F in Table 7 come from the answers to the question "On average, how much have you played League of Legends in the last month?". It exposes the

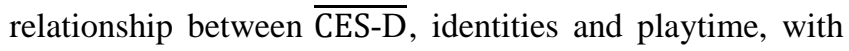
peripheral subgroups. Header letters mean: A, "I haven't played anything in the last month"; B, "Almost nothing, less than an hour a day and not every day"; C, "A little, between one hour and two hours a day"; D, "Reasonable, between two and three hours a day"; E, "A lot, between three and four hours a day"; F, "Very much, more than four hours a day".

\subsection{Mute}

The columns G, H, I, and $\mathrm{J}$ in Table 7 come from the answers to the question "Considering most of the time, have you blocked communication in the game this past month?". It

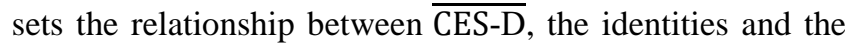
silencing behavior, with peripheral subgroups. Header letters mean: G, "I played with all communication open"; H, "Muted who says something I do not like or is not cool"; I, "I muted the enemy team"; D, "Muted everybody".

\subsection{Oppression}

The columns K, L, M, N, and $\mathrm{O}$ in Table 7 come from the answers to the question "At League of Legends, on any screen (match, lobby, home screen, etc.) have you noticed any oppression or social discrimination in the last month?". It sets the relationship between $\overline{\mathrm{CES}-\mathrm{D}}$, the identities and the perception of oppression, with peripheral subgroups. Header letters mean K, "No"; L, "Yes, directed at me"; M, "Yes, directed to another player(s)"; N, "Yes, not directed at anyone in particular"; O, "All previous 'Yes' options".

This analysis is subjectively sensitive, based on the assumption that the perception of oppression is often inherent to identity phenomena interpreted by the recipient (Grace, 2012). For example, racist communication can go unnoticed for a white man because it is not his experiential social place. Thus, the quantitative validity of data due to an essentially subjective apprehension of the respondent is not determinant of the phenomenon. However, we seek an interpretation from the data.

\subsection{Type of perceived oppression}

This question complements H4. All respondents who perceived oppression were requested to answer what category from a predefined list it was. The respondent could select from one to all eight available options:

- “LGBTphobia", related to life/sexual orientation.

- “Racism", related to skin color or race.

- “Sexism", related to sex or gender.

- "Fatphobia", related to body shape.

- “Ageism", concerning age or life stage.

- "Xenophobia", related to the origin/place of origin.

- "Financial situation", financial condition subjectively seized by the receiver.

- "Linguistic prejudice", related to linguistic variation, spelling, and grammar.

A self-declared response is associated with the meanings captured by the respondent and his interpretation of reality (Grace, 2012). In this question, 393 (65.07\%) of the 604 respondents have answered validly. Table 5 presents data from this category, e.g., 79 respondents who perceived two different types of oppression (e.g., sexism and ageism) resulted in 17 on the $\overline{\mathrm{CES}-\mathrm{D}}$ scale. 
Table 5: Types of oppression and their occurrence, by population

\begin{tabular}{||c|c|c|c||}
\hline \multicolumn{4}{|c|}{ Population perceiving oppression [393] } \\
\hline $\begin{array}{c}\text { Qty. of perceived types of } \\
\text { oppression }\end{array}$ & Qty. & Qty. \% & CES-D \\
\hline Noticed 1 type of oppression & 92 & 23,41 & $17(16,93)$ \\
\hline Noticed 2 types of oppression & 79 & 20,10 & $17(17,05)$ \\
\hline Noticed 3 types of oppression & 84 & 21,37 & $18(17,81)$ \\
\hline Noticed 4 types of oppression & 59 & 15,01 & $18(17,58)$ \\
\hline Noticed 5 types of oppression & 41 & 10,43 & $18(18,22)$ \\
\hline Noticed 6 types of oppression & 20 & 5,09 & $19(18,65)$ \\
\hline Noticed 7 types of oppression & 7 & 1,78 & $20(20,14)$ \\
\hline Noticed 8 types of oppression & 11 & 2,80 & $21(21,00)$ \\
\hline \hline
\end{tabular}

As dominant, $101(61.59 \%)$ of 164 respondents perceived at least one oppression; as peripheral, $292(66.36 \%)$ of 440. Dominants who perceived one or two oppressions had a CES-D value of 14 ; peripherals in the same parameters, 18. Table 6 shows the amount of specific oppression perceived by the respondents and its proportions based on the total population that perceived it (393).

Table 6: Types of oppression and their occurrence, by oppression

\begin{tabular}{|l|c|c||}
\cline { 2 - 3 } \multicolumn{1}{c|}{} & \multicolumn{2}{c||}{ Population perceiving oppression [393] } \\
\cline { 2 - 3 } \multicolumn{1}{c|}{} & Qty. & Qty. \% \\
\hline \hline Sexism & 264 & 67.18 \\
\hline Racism & 233 & 59.29 \\
\hline LGBTphobia & 213 & 54.20 \\
\hline Xenophobia & 138 & 35.11 \\
\hline Linguistic & 107 & 27.23 \\
\hline Fatphobia & 98 & 24,94 \\
\hline Ageism & 77 & 19.59 \\
\hline Financial & 70 & 17,81 \\
\hline \hline
\end{tabular}

Table 7: Quantitative data related to play time, muting and oppression, by identities

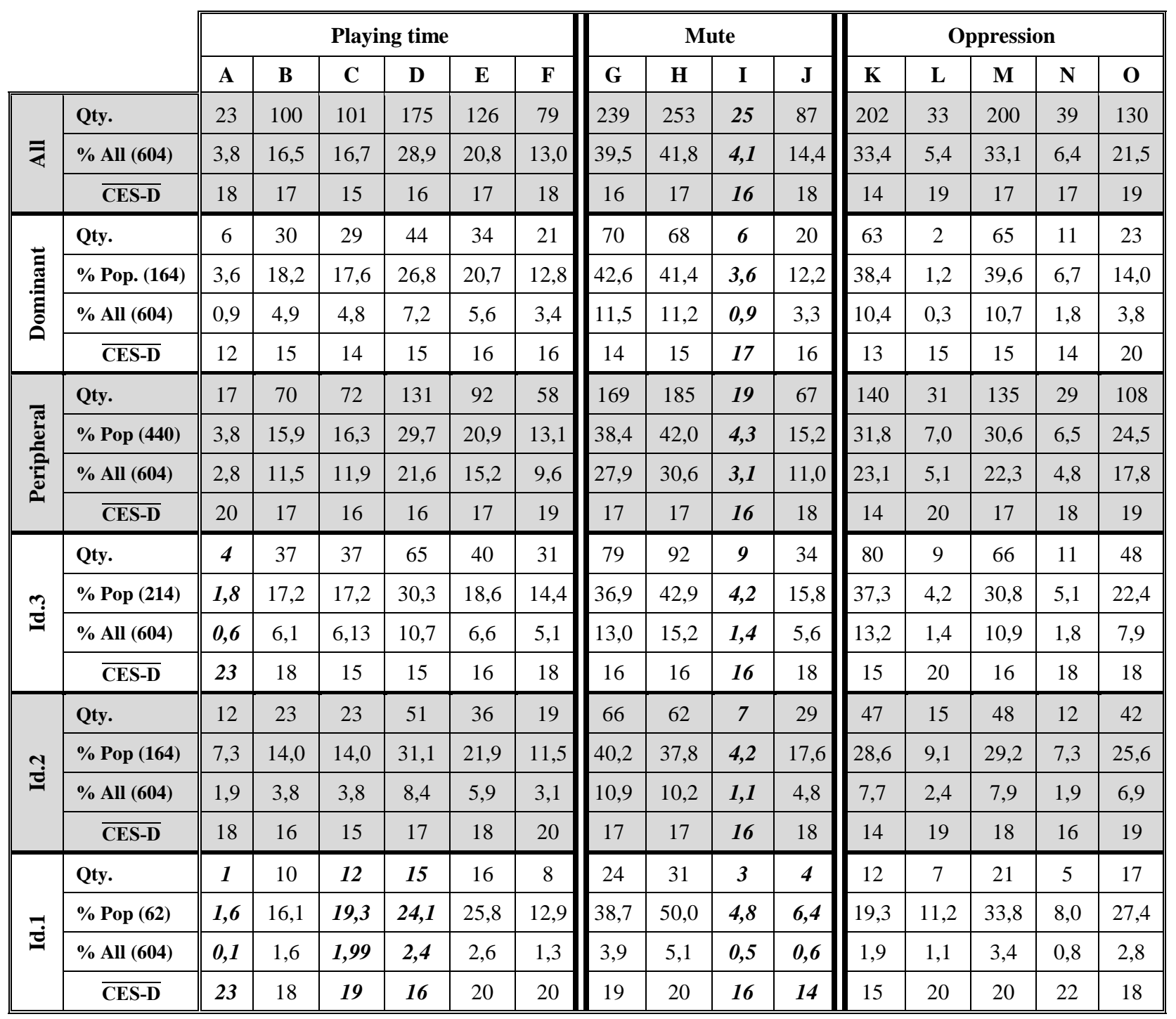

* Bold and italic styled data showed negligible amounts related to their respective populations, being quantitatively inexpressive. 
Table 7 summarizes structured data related to issues addressed in Sections 4.2, 4.3, and 4.4. The proportion is compared to the group itself and the entire population (604), analyzing the $\overline{\mathrm{CES}-\mathrm{D}}$ for that group and the specific question answer, indicated in the heading. For example, consider column $\mathrm{F}$, related to playing time, which indicates the answer "Very much, more than four hours a day". Both peripheral and dominant, comparing intra-group, have close results (13.1 and 12.8), even so, peripheral present $\overline{\mathrm{CES}-\mathrm{D}}$ 19, and dominant $\overline{\mathrm{CES}-\mathrm{D}} 16$.

\subsection{Hypothesis evaluation}

\subsubsection{H1: Dominants have lower scores when compared to peripherals}

We confirm H1 through the data in Table 1. There is no CES-D form comparative absolute result to be used as a universal parameter of comparison (Radlof, 1977), so the anchor value was the comparison based on $\overline{\mathrm{CES}-\mathrm{D}}$ of the population (16). The screening of depressive disorder is 2 points more expressive for peripheral (17) than dominant (15).

The value for peripherals worsens as it distances itself from the dominants, with 16 for id.3, 17 for id.2, 19 for id.1. In addition to being confirmed, the hypothesis is attenuated to id.1, with a difference of 4 points for dominants. Id.3 is equal to the overall $\overline{\mathrm{CES}-\mathrm{D}}$ (16). We can assume this group partially enjoys the social privileges of the dominant identities, does not reach them, and does not present a worse result than the general population, such as id.2. The distance from dominants is proportional to the chance of being affected by negative social interactions.

For an id.1 player, the trend is likely to be a higher score, i.e., tracking for depressive disorders due to LoL interactions. It is perceived that as identity deviates from dominance, the population quantity below the general $\overline{\mathrm{CES}-\mathrm{D}}$ number (16) becomes greater. The data express a positive reality ( $49 \%$ above, $51 \%$ below), analyzing the entire population, although for id.1 this reality is significantly different, much worse $(67.7 \%$ above and $32.3 \%$ below). This information shows the importance of analyzing social groups for their differences and specificities, not as a single homogeneous set. The overall picture is positive, while for a sub-group, it is negative.

A peripheral, id.3, holds the highest CES-D (44). The largest CES-D of a dominant is 6 points lower (38). Including these, among the worst value of peripherals and dominants CES-D scale, five are peripherals, ranging from 38 to 44 .

Figure 4 exposes the relationship between social identities and respective $\overline{\mathrm{CES}-\mathrm{D}}$. It represents the sum of identity population with certain $\overline{\mathrm{CES}-\mathrm{D}}$ in comparison to the $\overline{\mathrm{CES}-\mathrm{D}}$ obtained. The dominant peak occurs before the others, $7.9 \%$ of dominants score $9 ; 8.8 \%$ of id.3 scores 13 ; $9.1 \%$ of id. 2 scores $17 ; 11.2 \%$ of id. 1 scores 16 . As identity distances itself from social dominance, the influence of LoL on depressive disorder behaviors becomes more perceptible and expressive.

Figure 5 displays a graphical smoothing of lines by grouping the $\overline{\mathrm{CES}-\mathrm{D}}$ values in groups of three for better visualization of behaviors. At this point, a deepening of the perceived phenomenon in Fig. 1 and 2 is relevant. We could assume that the best possible scenario would be the Y-Axis marks at $100 \%$ ordered to the value 0 of the $\mathrm{X}$-Axis, as no player would have any point traced to depressive disorders.

At a higher level, two factors build the behavior of this graph data (Adams, 2014): (i) game external - when there is a dialogical relationship between identity subjectivity and the universe of the player's external experiences within the game; (ii) gameplay - the game brings the player closer to their mental limits in a healthy way, as frustration and shock of expectations enriches the experience of playing. For example, in LoL, to feel like crying for not reaching higher levels in competitive positions (raise their Rank or Elo) is a healthy phenomenon, if not frequent, when considering the competitive and social category of experience (Adams, 2014).

The problem appears when, due to in-game experience, different identities present $\overline{\mathrm{CES}-\mathrm{D}}$ values vastly different, as exposed in Figures 4 and 5. The experience of playing tends proportionally to depressive disorder as identity has fewer dominant social attributes. But not only that, the best graphical behavior for the curve's peak is also occurring as close as possible to 0 on the X-Axis. Figures 3 and 4 show how the values between $10 \%$ and $15 \%$, more distant on the $\mathrm{X}$-Axis, are in higher quantity as more as the identity becomes peripheral.

Lines representing each social group should approximate and overlap. Even if a problematic number of players were away from the $0, \mathrm{Y}$-axis, social groups would still expose social experiences related to depressive disorder behaviors nearby, and even if inadequate, it would nullify the hypothesis of social inequality. We can naively believe that "all lines must overlap". However, by doing so, we would neglect that there is already a reality external to the game and that there is no solid border between intra-game and extragame. In this research, the distance between the lines in Figures 4 and 5 exposes that social inequality, and the consequent problem, are explicitly observable.

The Gaussian distribution is another way to represent the quantitative behavior graphically, as shown in Figures 6 and 7. The density and accumulated distribution functions are divided by identities (Agresti et al., 2017). Dominants have their $\overline{\mathrm{CES}-\mathrm{D}}$ peak before the others. The more peripheral, the curve's peak will shift to the right and assume greater values. The interquartile range moves in intervals with higher values as we analyze a more peripheral identity.

Ranging from 0 to 17 , we always have fewer peripheral identity individuals than dominant ones. From 18 onwards, this relation inverts. As we increase the CES-D value, the chance of being peripheral becomes greater.

Figure 7 shows the probability of finding a certain CESD value in each identity. In $\overline{C E S-D} 16: 35 \%$ for id. $1 ; 47 \%$ for id.2; $47 \%$ for id.3; and $56 \%$ for the dominant identity. As the 
id. 4 curve precedes the others, it shows us that its image has a smaller interval. Thus, id.4 assumes lower CES-D values than the others, just as id.3 assumes lower values than id. 2 and id. 1 and so on.

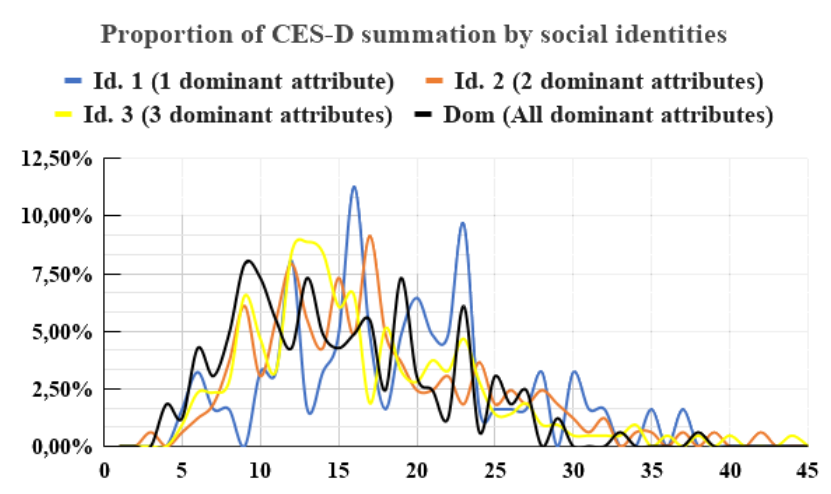

Figure 4: CES-D linear graph by social identity

Proportion of CES-D summation by social identities (group of 3 )

- Id. 1 (1 dominant attribute) - Id. 2 (2 dominant attributes)

- Id. 3 (3 dominant attributes) - Dom (All dominant attributes)

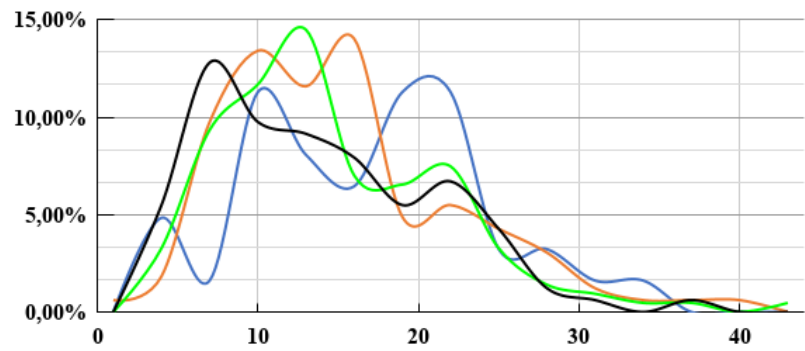

Figure 5: CES-D linear graph by social identity (groups of 3)

CES-D probability density function by identities

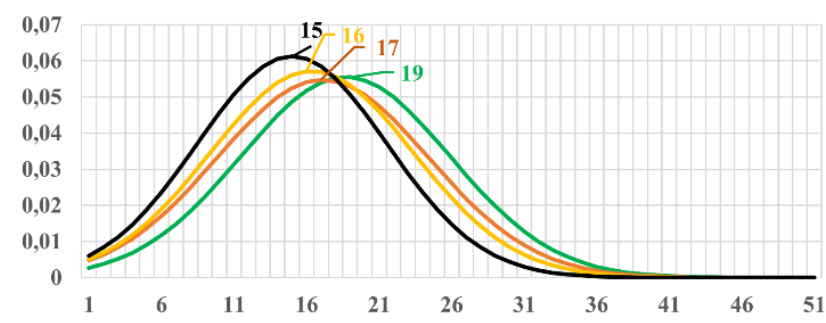

-Id. 1 -Id. $2-$ Id. $3-$ Id. 4

Figure 6: Probability density function by identity

CES-D cumulative distribution function by identities

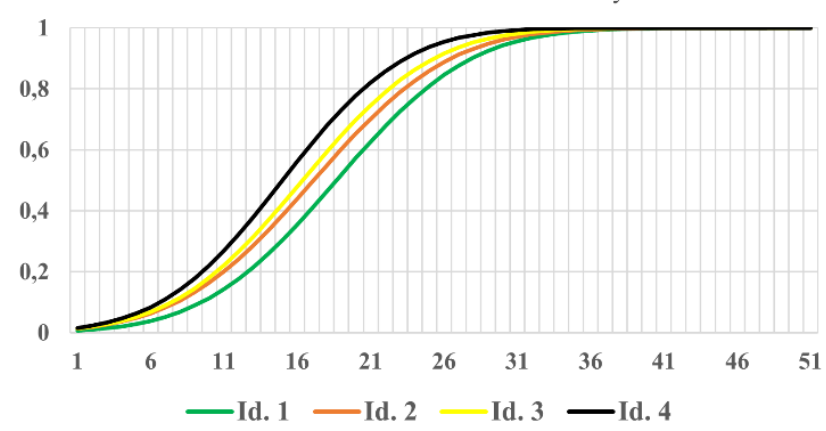

Figure 7: Distribution function by identity

\subsubsection{H1 Correlated hypotheses (H1.1 to H1.4)}

We confirmed H1.1 male score lower compared to nonmales, and H1.2 heterosexuals score lower compared to non-heterosexuals.

We refute H1.3 whites score lower compared to nonwhites, and H1.4 South and Southeast score lower compared to Midwest, North, and Northeast.

Regarding gender, the $\overline{\mathrm{CES}-\mathrm{D}}$ difference between male and non-male is the largest between peripheral and dominant (3 points). The male population $\overline{\mathrm{CES}-\mathrm{D}}$ (16) is equated with the general population (16), exposing it is not enough to identify as "male" to equate with dominants (15).

Table 4 points out this specific attribute by having the highest significant difference for the general average (16), $63.74 \%$ of non-male players score less than the overall average, and $53.61 \%$ of males are below. Thus, it demonstrates that the scenario is mentally healthier for males.

However, not only non-masculine $\overline{\mathrm{CES}-\mathrm{D}}$ is higher, but also most individuals in this population are below the overall average. Quantitatively, gender was the worst identity result among all four attributes analyzed.

Regarding sexual orientation, quantitative behavior resembles H.1.1 analysis, attenuated. The difference between the non-heterosexual population $\overline{\mathrm{CES}-\mathrm{D}}$ (18) is two points higher than the heterosexual population (16). Again, we realize that it is not enough to identify as "heterosexual" to equate them with dominants (15). Most non-heterosexuals $\overline{\mathrm{CES}-\mathrm{D}}(54.42 \%)$ are generally positioned higher than heterosexuals, and heterosexuals lower than nonheterosexuals (53.98\%).

Regarding skin color, quantitative behavior resembles the analysis of H.1.1 and H.1.2, attenuated. The difference between the non-white population $\overline{\mathrm{CES}-\mathrm{D}}$ (17) is one point higher than the white population (16). Again, we realize that it is not enough to identify as "white" to equate with dominant $\overline{\mathrm{CES}-\mathrm{D}}$ (15). Most non-white $\overline{\mathrm{CES}-\mathrm{D}}(52.03 \%)$ are higher than whites, and whites are lower than non-whites $(52.34 \%)$.

Figure 8 compares all identities in a box chart (Agresti et al., 2017), enabling a statistical comparison between all social attributes.

Despite the difference by approximation, H.1.3 is not statistically significant $(\mathrm{p}=0.180)$, i.e., refuted. Variance is inconclusive to the phenomenon. Without approximation, they differ in 0.8 points on the CES-D scale.

Regarding region of origin, the difference between the Midwest, North, and Northeast regions population CES-D (16) is one point less than in the South and Southeast (17). Nevertheless, compared with the general average, the proportion follows the other $\mathrm{H} 1$ correlated hypothesis. The majority identified as Midwest, Northeast, and North regions $(52.27 \%)$ score higher $\overline{\mathrm{CES}-\mathrm{D}}$ than the other ones and vice versa $(52.34 \%)$. Again, it is not enough to identify as from Midwest, North, and Northeast regions to equate with the dominant (15). 


\section{Comparison between identities and attributes}

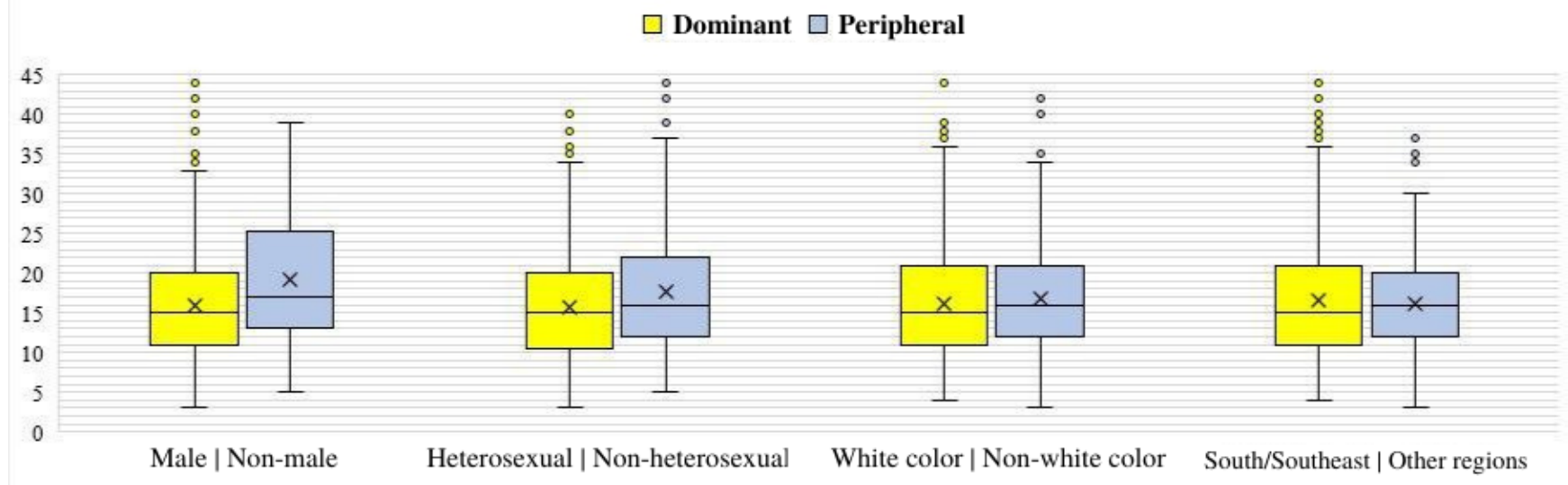

Figure 8: Boxplot chart of Identity and Attributes by CES-D average

With H.1.4 refuted, the ideal scenario would be that the two values would equate with the overall mean (16). Future studies may deepen this specific hypothesis, considering that it disagrees with commonly established social perception, such as xenophobia.

\subsubsection{H2: Playing time increases the score of peripherals compared to dominants}

Table 7 data confirms H2. Regarding Table 7 and Column A, respondents have not played in the last month. They were not exposed to the game and its aspects for a month or more. However, we consider this category valid for their experience and relationship with the game. Considering the values of generally dominant $\overline{\text { CES-D }}$ (12) and peripheral (20), we noticed that not playing was mentally beneficial for dominants, but not necessarily for peripherals. In this case, we assumed that trauma and negative interactions were expressive to the point that, even a month later, players still present remnants of negative memories which influence their mental health, pointing to depressive disorders.

Table 7 and Column B explain that playing up to an hour a day and not every day has a worse result when compared to playing between one and two hours every day, Column C, for all identities. We assume that the experiences of this group, although few, are negatively significant as they are punctual and concentrated, i.e., the limited experience of only one or two matches, approximately one hour, is negative.

Table 7 and Columns C, D, E, F expose that, regardless of identity, the $\overline{\mathrm{CES}-\mathrm{D}}$ aggravates proportionally to playing time and proportionally inversed to the identity position. The more peripheral and longer playing time, the greater the tracking for depressive disorders. According to this result, the appropriate for mental health is to play between one and two hours daily. Disregarding id.1, which presented inconsistent data in Columns A, C, D, all other identities presented lower results than the general average (16) in Column C. Even the dominant had an improvement in the score, of less than one, when compared to their own $\overline{\text { CES-D }}$ (15).
In all cases, playing four hours or more pointed to worse results compared to the identity's $\overline{\mathrm{CES}-\mathrm{D}}$. The impact of playing time is less expressive in dominants. In the worst case, the $\overline{\mathrm{CES}-\mathrm{D}}$ (16) is equivalent to the overall population $\overline{\mathrm{CES}-\mathrm{D}}$ (16).

\subsubsection{H3: Muting increases peripheral scores compared} to dominants

H3 is refuted/not significant through data in Table 7.

Unlike playing time, each column must be analyzed separately. Column $\mathrm{G}$ points to respondents that play with all communication enabled from their team and the enemy team. Enabled communication does not significantly influence the CES-D result.

Table 7 and Column $\mathrm{H}$ points to players that have silenced one or more players, allies or opponents. It follows the same behavior observed in Column G, except for id.1. In the case of id.1, the $\overline{\mathrm{CES}-\mathrm{D}}$ is one point higher than their identity $\overline{\text { CES-D }}$ (19). The difference between players that mute someone and players that keep all communication enabled is $11.2 \%$. Of all identities, Columns $\mathrm{G}$ and $\mathrm{H}$ have the greatest difference. We completely disregarded the results of Table 7 and Column I due to quantitative inexpressiveness.

Table 7 and Column J, disregarding id.1 due to inexpressiveness, points to a problematic phenomenon. Players that mute everyone else (including allies) present worse $\overline{\mathrm{CES}-\mathrm{D}}$. Thus, silencing all other players influences mental health negatively. This data contradicts the common sense that "ignoring messages of others will preserve my psyche". The amount of population that silences all other players is proportional to its position in the identity hierarchy. This data points out that dominants (12.2\%), compared to other players, are more comfortable with open communication, and id.2 (17.6\%) opts for silencing. That was the only significant dimension of $\mathbf{H 3}$ if analyzed separately.

Compared to general population $\overline{\mathrm{CES}-\mathrm{D}}$ (16), (i) dominant identities are not influenced negatively by the 
muting act, but rather, open communication positively affects the mental health of this population (14); (ii) peripherals, together, silence others $(42 \%)$ instead of using all communication available $(38.4 \%)$.

\subsubsection{The perception of oppression increases the peripheral scores when compared to dominants}

\section{H4 is confirmed through data in Table7.}

Table 7 and Column K reassure an obvious conclusion: players who do not perceive any oppression present better $\overline{\mathrm{CES}-\mathrm{D}}$ than those who perceive any type of oppression, whether dominant or peripheral. LoL experience without toxic social interactions positively impacts the $\overline{\text { CES-D }}$ results. Table 8 compares the identity population or group and general group.

Table 7 and Column L indicate that peripherals that perceive oppression solely directed to them present $\overline{\mathrm{CES}-\mathrm{D}}$ (20) three points higher than the peripherals grouped (17). Although only two dominants declared that they perceived oppression solely directed to them, they have the same $\overline{\mathrm{CES}-\mathrm{D}}$ as the dominant group (15) and lower than the overall population (16). Also, identifying as "victims of oppression" did not affect them as much as it affected peripherals in the same situation.

Table 8: Data indicating better CES-D results without oppression

\begin{tabular}{||l|c|c|c|c|c|c||}
\hline \hline CES-D Comparison & All & Dom. & Per. & Id.3 & Id.2 & Id.1 \\
\hline Without oppression & 14 & 13 & 14 & 15 & 14 & 15 \\
\hline Identity (specific)* & -2 & -2 & -3 & -1 & -3 & -4 \\
\hline General (16) & -2 & -3 & -2 & -1 & -2 & -1 \\
\hline Group (15 and 17) & & -2 & -3 & -2 & -3 & -2 \\
\hline
\end{tabular}

* As shown in Table 2: All, 16; Dom., 15; Per., 17; id.3, 16; id.2, 17 ; id.1, 19.

Table 7 and Column M point to players who have noticed oppression only directed to others. Results indicate that perceiving oppression directed to others does not influence mental health of dominants. Matching its population $\overline{\text { CES-D }}$ (15), dominants that perceive oppression directed to others $(39.6 \%)$ is higher than peripheral $(30.6 \%)$. Unexpectedly, id.3 that perceive oppression presented $\overline{\text { CES-D }}$ one point lower (16) compared to the peripherals group $\overline{\mathrm{CES}-\mathrm{D}}(17)$. Considering this isolated data, we suppose that perceiving oppression against others is a positive phenomenon for id.3 mental health. That is plausible as quantitative analysis but not as qualitative. Nevertheless, it indicates future work.

Concerning Column $\mathrm{N}$ of Table 7, we noticed that dominants non-directed oppression, without specific targets, present positive results, one point lower (14) than their $\overline{\mathrm{CES}-\mathrm{D}}$ group (15). According to theories about empathy and indirect somatization (Grace, 2012), peripherals that perceive this phenomenon present higher $\overline{\mathrm{CES}-\mathrm{D}}$ (18) than the overall population (17). After highlighting and analyzing in-depth id.2 data, we were not able to interpret the reason why their $\overline{\mathrm{CES}-\mathrm{D}}$ is three points lower (16) compared to its specific population $\overline{\text { CES-D }}$ (19). This result seems incoherent compared to other peripherals. A possible explanation may be the respondents' amount (12). Likely, non-directed oppression may be ineffective on them, and this indicator was incidental; unlikely, considering literature, they perceive it as distractive or entertaining.

Table 7 and Column $\mathrm{O}$ expose that overall oppression has greater influence on dominants compared to peripherals. In this case, peripherals have two points less in $\overline{\mathrm{CES}-\mathrm{D}}$ (19 to 17), and dominants have a significant decline of five points (20 to 15). The more peripheral the identities, the greater the respective population that perceives all options of oppression (id.3, 22.4\%; id.2, 25.6\%; id.1, 27.4\%).

We interpret the higher $\overline{\mathrm{CES}-\mathrm{D}}$ value for dominants compared to peripherals as a reason of conscientious impact (Grace, 2012). Dominant identities (i) are not used to live with concrete oppression in their ambiances; (ii) are not aware or instructed to recognize oppression, especially when subtle; (iii) are positively elected to the symbolic and nonconcrete universe of discourse, e.g., reframing oppression as "jokes" and invalidating their negative value to the others' psyche. Thus, effectively perceiving situations of oppression sums up a reality check. There is a socio-cultural and affective paradigmatic change impacting them more than a social group that deals concretely with this conflicting identity phenomenon, since its emancipation and apprehension. All presented values equivalent to the dominant $\overline{\mathrm{CES}-\mathrm{D}}$ (15) are lower than the general column $\overline{\mathrm{CES}-\mathrm{D}}(16)$, explaining why the $\overline{\mathrm{CES}-\mathrm{D}}$ result differentiates from column $\mathrm{O}$ to $\mathrm{K}, \mathrm{L}, \mathrm{M}, \mathrm{N}$. Therefore, concrete social oppression affects these dominants.

\subsubsection{Amount of perceived oppression}

We noticed a $\overline{\mathrm{CES}-\mathrm{D}}$ proportional growth related to the number of oppressions. Regardless of dominant or peripheral groups, having perceived at least one type of oppression equates to peripheral $\overline{\mathrm{CES}-\mathrm{D}}(17)$. From this point on, results worsen, reaching four points more (21), which is significantly high for players that perceived eight oppressions from listed options.

Table 6 exposes the worst scenario for non-male, nonwhite and non-heterosexual identities. More than $50 \%$ of respondents that perceived some oppression recognized these as most frequent. The results in Section 4.6.2 are aligned with this reality. Table 2 results track attributes pointing to the greatest amount of oppression.

\subsubsection{Hypotheses formal evaluation}

H1, H2, H3, H4 were statistically evaluated. A table with details from the analyses is available online ${ }^{8}$. We conducted an analysis of variance (ANOVA), F test, and $p<0.05$

\footnotetext{
${ }^{8}$ https://cutt.ly/pdxHAkp. Accessed: 01 January 2021
} 
significance level. Considering correlated hypotheses: H1, H1.1 and H1.2 were statistically confirmed; H1.3 and H1.4 were statistically rejected $(\mathrm{p}=0.180$ and $\mathrm{p}=0.709)$; only $\mathrm{H} 3$ was refuted $(\mathrm{p}=0,304)$.

\section{Qualitative analysis}

Each subsection details a specific issue. The quantitative analysis used in this part of the research serves as a basis for qualitative ones. Subjectivity and intended breadth of depth are incompatible with numerical generalizations.

As Merriam and Tisdell (2015) and Bhattacherjee (2020) recommend this approach, we analyze the discursive responses as qualitative documentation, respecting the respondents' subjectivity. The procedure starts with screening, we analyze each response in depth; we evaluate its pertinence, since being a discursive field, jokes or disconnected contents from the context can arise; we separated the responses considered question specific. As a next step, "Coding is nothing more than assigning some sort of short-hand designation to various aspects of your data so that you can easily retrieve specific pieces of the data" (Merriam and Tisdell, 2015), that is, we parameterize the speeches and its elements. The categorization stage processes these parameters and synthesizes them qualitatively into categories, in this case we use an incremental and grounded categorization exclusively on the data, eliciting relevant phenomena and knowledge from them; we do not use a ready-made base of categorical constructs. It is a process that goes from inductive to deductive.

\section{1 "Does the number of hours played per day change depending on something?"}

The pre-determined options for this question aim to analyze variations of player behavior related to playing time. Not capturing all the complexity of possible actions supports the perception of Section 4.2. Significant discrepancies motivated us to analyze the phenomenon specifically. Variations with considerable response amount showed a CES-D value of at most 2, both for identity and social group. Therefore, we disregarded deepening each option. Specific discrepancies will be pointed out on a case-by-case basis. For example, as shown in Table 2, the overall CES-D is 16, the categories listed below remained between 14 and 18 , quantitatively meaningless.

“On Weekend/holiday/free days, I play more": most selected option, with $68.54 \%$ (414) of respondents. A quantitatively normal behavior across social groups, presenting only a $5.9 \%$ variation between the two ends (id.4 with $68.29 \%$, and id.1 with $74.19 \%$ ).

"On working/week/busy days, I do not play": selected by $30.63 \%$ (185) of respondents. In this option, we noticed a discrepancy of $10.48 \%$ between id.4 (25\%) and id.1 $(35.48 \%)$. Comparing to dominants, we interpret id.1 as unlikely to enjoy playing on days considered traditionally busy. Id.1 CES-D improved by two points (19 to 17), as $28.18 \%$ (22) selected this option.
"I play/want to play as a professional or e-sport competitor. I play much more": least selected option, with $5.13 \%$ (31) of respondents. The respondent amount did not allow us to make a significant quantitative assessment. CES$\mathrm{D}$ values of all social groups are worse compared to those presented in Table 2. That may be related to pressure, exhaustive amounts of consecutive matches, and continuous social interactions excess within the game. Deepening this specific player category may fit another focused research.

"I play more when I am with my friends": selected by $44.21 \%$ (287) of respondents. A quantitatively normal behavior across social groups, presenting only a $5.27 \%$ variation between the two ends (id. 4 with $46.34 \%$ and id. 1 with $51.61 \%$ ).

"If I am alone, I do not play": selected by $14.24 \%$ (86) of respondents. A quantitatively normal behavior across social groups, presenting only a $4.94 \%$ variation between the two ends (id.4 with $12.80 \%$, and id.1 with $17.74 \%$ ).

"If I start to lose, I stop for a while, or that entire day": selected by $29.30 \%$ (177) of respondents. A quantitatively normal behavior across social groups, presenting only a $5.16 \%$ variation between the two ends (id. 3 with $27.10 \%$, and id.1 with $32.26 \%$ ).

"I want to win, so I insist on playing until I win... or giving up": selected by $15.73 \%$ (95) respondents. We did not observe a behavioral pattern in the results: id.4 (12.20\%); id.3 (12.15\%); id.2 (22.56\%); and id.1 (19.35\%). All social groups got worse CES-D in this category, two points higher. Only respondents from id.1 maintained the same CES-D (19). This option can mean gambling addiction and a noteworthy factor in results, but that is not this work scope.

"I play more when there is a game event": selected by $39.40 \%$ (238) of respondents. There is a pattern to tension in this specific category: id.4 (31.71\%); id.3 (40.19\%); id.2 $(41.46 \%)$; id.1 (51.61\%). There is a $19.90 \%$ variation between the two ends. The CES-D change was meaningless, only about one in some social groups.

Award events are an award-winning and gamification initiative within the game. The more they play or perform missions, the better the prizes they get. Some players perceive this practice as "company altruism", since "they are not paying" for the object in question. A speech commonly found through the community is: "don't complain, they are already giving you [the specific award] for free" reifying players' time, effort, and dedication (Boscagli, 2014), bringing the scenario closer to a "beneficence" category, while concretely, it is a "hooking" mechanism (Eyal, 2014).

This option can mean economic inequality, added to social inequality, but this is not this work scope. However, we take the responsibility of presenting a brief interpretation of these values.

Cosmetic elements (skins), non-functional, are socioculturally perceived as prestigious in the LoL community. They convey certain values to players, and there is a dialogical relationship between economic and social aspects. As respondent \#477 points out, it is synonymous with social status and privilege. 
The game has its currency, "Riot Points" (RP), purchased with real money. The most expensive skin class available for purchase is called "Ultimate", reaching a price of 3,250 RP. To acquire an ultimate skin, the player needs to pay around $\mathrm{R} \$ 60$, as a package with 2,800 RP costs $\mathrm{R} \$ 54.50$ (February 2021). For someone in a precarious economic situation, with only a regular computer and paid internet, attending an event, and aiming its rewards, are ways to acquire a status object. That would potentially offer them a socially positive experience, giving them prestige and positive visibility in the community.

For external viewers, this phenomenon can cause strangeness. For players immersed in the community, universe, and game itself, this prestige is analogous to displaying an expensive watch or bracelet, or to nice results of a hair treatment or manicure. Some of us authors, and also LoL players, have already seen positive social interactions related to cosmetic effects directed to us, by us, or to third parties.

For someone in a precarious economic situation, events and awards are an opportunity to cause a positive social impression. Indeed, this is supported by our data and by Brazilian socio-material reality (IMDS, 2020). To the dominants, this effect may not be psychologically expressive, as they can pay (or have someone to pay for them) the price charged by the game; while to peripherals, the option is to "conquer" this effect through their own time and effort, to enjoy same prestige, and socially perceive themselves as "something more".

Ferreira et al. (2020) associate the phenomenon of acquiring cosmetic elements to the Fear of Missing Out (FoMO), i.e., players would like to enjoy the same rewarding experiences as others do. Players in a precarious economic situation will use events as a means of inclusion.

"I take breaks between matches. I do not play without stopping": selected by $18.05 \%$ (109) of respondents. In this option, we noticed a discrepancy of $10.66 \%$ between id.4 (21.95\%) and id.1 (11.29\%).

CES-D results had insignificant variation, disregarding id. 1 result, of only $7(11.29 \%)$ respondents. Taking breaks between matches, behavior reported by dominants, is a possible mechanism to alleviate toxic social interactions.

The qualitative and quantitative impact of answers to this question was little. Population discrepancies did not exceed $11 \%$ of the interval between extremes, and the CES-D variance did not exceed 2. Superficially, respondents' amount values can expose particular phenomena by themselves. They can be detailed in future works, e.g., analyzing the outcome of players that intend to be professional players or formally detailing the association between participation in-game events and the ambition for positive social interaction through "rewards".

\section{2 "Was I (or others said I was) toxic, negative?"}

As a complement to CES-D evaluation questions, we intend to discover this research's thesis complement. Instead of analyzing the influence of social interactions on CES-D, we analyze the respondents' perception of their interactions and their respective CES-D. That is, to consider players as active agents, which influences others' CES-D.

Table 9 involves the question "Was I (or others said I was) toxic, negative?" and its results are groundbreaking. As expected, similar to a negative exponential function, most players pointed out that they do not feel or remember being toxic, and less than $10 \%$ stated explicitly that they were almost always toxic.

CES-D is significantly proportional to the perceived frequency of its toxicity for peripherals and each identity that composes it. The value follows Table 2 tendency. Perceiving themselves as toxic almost always affects CES-D of id.1 (34) more than id.3 (24). Results might increase depending on response and how far they are from dominants.

In contrast, dominants had a lower CES-D and improved at perceiving themselves as sometimes (21) or almost always (19) toxic. At first, one can suspect an inaccuracy "almost always" result, only $7(4.26 \%)$ answers. However, the quantitative behavior of all other social groups is consistent and numerically similar. Certain dominants are aware that they are almost always toxic, but that does not impact their CES-D. By analyzing them seven separately, four appear not influenced by the moral epistemic responsibility of their social interactions, presenting CES-D results remarkably close to or below the dominant social group as a whole (15). The other three scored a CES-D significantly higher $(22,25$, and 29). In the same category, of all other identities' individuals (17), only one id.2 and one id.3 presented CESD lower than their respective social groups.

Table 9: CES-D based on declared toxicity

\begin{tabular}{|l|c|c|c|c|}
\cline { 2 - 5 } \multicolumn{1}{c|}{} & $\mathbf{0}^{*}$ & $\mathbf{1}^{*}$ & $\mathbf{2}^{*}$ & $\mathbf{3}^{*}$ \\
\hline Overall (604) & 357 & 168 & 55 & 24 \\
\hline Overall \% & 59.11 & 27.81 & 9.11 & 3.97 \\
\hline CES-D & 15 & 17 & 20 & 24 \\
\hline id. 1 (62) & 39 & 13 & 8 & 2 \\
\hline id. 1\% & 62.90 & 20.97 & 12.90 & 3.23 \\
\hline CES-D & 17 & 20 & 18 & 34 \\
\hline id. 2 (164) & 103 & 41 & 13 & 7 \\
\hline id. 2\% & 62.80 & 25.00 & 7.93 & 4.27 \\
\hline CES-D & 16 & 18 & 21 & 28 \\
\hline id. 3 (214) & 125 & 59 & 22 & 8 \\
\hline id. 3\% & 58.41 & 27.57 & 10.28 & 3.74 \\
\hline CES-D & 15 & 18 & 20 & 24 \\
\hline id. 4 (Dom. 164) & 90 & 55 & 12 & 7 \\
\hline id. 4 (Dom.) \% & 54.88 & 33.54 & 7.32 & 4.27 \\
\hline CES-D & 13 & 16 & 21 & 19 \\
\hline Per. (440) & 267 & 113 & 43 & 17 \\
\hline Per. \% & 60.68 & 25.68 & 9.77 & 3.86 \\
\hline CES-D & 15 & 18 & 20 & 27 \\
\hline
\end{tabular}

* 0: I did not feel or do not remember; 1: Once or a few times; 2 : Many times; 3: Almost always.

Psychological recoil is objectively worse to peripherals compared to dominants. From Schulman's perspective (2016), peripherals project oppressions and symbolic aggressions, suffered in-game, on their social interactions, 
added to external factors. This projection affects other players, peripheral or not, but mainly themselves. Variation between results of columns 0 to 3 , in Table 9 , is 12 for peripherals and 8 for dominant. Besides, it is invalid that dominants "project suffered oppression". Potentially, this social group presents sociopathic, ethically perverse, and immoral individuals. These individuals benefit/are insensitive to social consequences their symbolic oppression and aggression may cause (Sidanius and Pratto, 1999; David and Derthick, 2017).

Not feeling or remembering toxic interactions has a significant positive CES-D influence. All social groups, including the dominant, were benefited.

We allocate this analysis as mixed, for there is causality indeterminacy, subjectivity, and individuals CES-D influence on this behavior or vice versa. Are individuals toxic and project toxicity on the environment, or is the environment toxic and project toxicity on individuals?

\section{3 "Freely, how do you feel about social interactions in League of Legends? How would you describe them?"}

The question is open and discursive. After treatment and normalization, we analyzed 392 valid responses. Table 10 shows the quantitative analysis of this issue. The vast majority of players feel that social interactions in the game are negative. The sum of all other options is less than "negative". The exclusively positive responses occurred to a lesser extent. Dualistic responses point to ambiguous interpretations, both positive and negative. Neutral responses omitted evaluation, as did respondent \#29: "Normais" (Normal).

Table 10: CES-D based on social interaction feelings

\begin{tabular}{|l||c|c|c|c||}
\cline { 2 - 5 } \multicolumn{1}{l|}{} & Negative & Positive & Dualistic & Neutral \\
\hline \hline Overall (386) & 211 & 51 & 79 & 45 \\
\hline CES-D (16) & 17 & 14 & 16 & 16 \\
\hline Dom. (94) & 52 & 14 & 17 & 11 \\
\hline Dom. \% & 55.32 & 14.89 & 18.09 & 11.70 \\
\hline CES-D (15) & 15 & 12 & 16 & 12 \\
\hline Per. (292) & 159 & 37 & 62 & 34 \\
\hline Per. \% & 54.45 & 12.67 & 21.23 & 11.64 \\
\hline CES-D (17) & 18 & 15 & 16 & 17 \\
\hline \hline
\end{tabular}

Although considered data is only a sample (386) of total data (604), the intention is to compare by generalization. As expected, players with positive perceptions had better CESD compared to their respective social groups, shown in Table 2. The other dimensions showed a maximum variance of 2 , disregarding the "neutral" result from dominants with an insignificant amount. Perceiving negativity does not affect the dominant group CES-D, which may indicate apathy or insensitivity.

After analyzing all responses, we coded and categorized central ideas and concepts associated with social interaction to extract knowledge from responses, generating perceptions of reality. As qualitative contributions, quantitative parameters are secondary or inconsiderable. The question title points to a deterministic direction. However, the analysis respected the respondents' spontaneity and autonomy of testimony.

The most common discrimination is explicitly against females or elements of femininity, reinforcing the quantitative hypotheses. To "hide" feminine gender in communications is a defense mechanism to prevent oppression or gender discrimination, thus endangering their healthy identity. Female nicknames, explicit or not, present an objective risk of oppression aimed at women or men using female nicknames. For example, respondent \#390 uses a nickname that contains "Juuh" (we omit the entire nickname to preserve privacy). He is a man named Junior, but he constantly reports being a target of gender oppression. Others may conjecture that he is a woman, as "Juuh" is a popular alias for Juliana.

There is a negative dialogical relationship when the oppressed respond similarly. This negative dialogical relationship of toxic interactions causes what we call "asymmetric punishment": when an initially oppressed player is punished, the company justifies it with a speech promoting docile and crooked civility.

For example, when player B calls player A "dirty nigger", player A addresses B: "and you are an asshole". Some testimonies from players aligned with A's situation indicate that they were punished. In this case, we perceive false discursive symmetry and an unfair categorical imperative of the company to punish the oppressed. To offend a player as an "asshole" during a match is reprehensible, (i) unless they are two different weights aimed at different identities individuals. Comparing racial injury with a neutral offense is morally incoherent and encourages a sense of impunity. The oppressed is expected to be "civilized" and "to follow moral guidelines of the game", even though they did not trigger the scenario that punished him as a result. (ii) As the quantitative analysis exposed, to use unfair categorical imperative disregards the factors of oppression external to the game. This line of action reinforces the feeling of discrimination and oppression that players flee when resorting to the game. Considering this hypothetical isolated episode, to punish both players equally is unfair and harmful to the psychosocial health of player A, who dared to react.

Twenty-one players prioritize playing with colleagues, and most of them classify social interaction in the game, in general, as negative. Several players avoid interactions in fear of negative experiences, regardless of the scenario, reinforcing the defense mechanisms against oppression pointed out by Schulman (2016). 
5.4 "If you could send one, and only one, suggestion for improvement to the game team that would be immediately obeyed, which would it be?"

This question is open and discursive. After treatment and normalization, we analyzed 463 valid responses. Table 11 shows the quantitative analysis of this issue.

Table 11: Improvement suggestion type by social group quantity

\begin{tabular}{||l|c|c|c|c||c||}
\cline { 2 - 6 } \multicolumn{1}{c|}{} & Tech. & Social & Org. & Irrel. & Pun. \\
\hline \hline All (647) & 273 & 181 & 22 & 66 & 105 \\
\hline All \% & 42.19 & 27.98 & 3.40 & 10.20 & 16.23 \\
\hline id. 1 (46) & 26 & 22 & 1 & 6 & 16 \\
\hline id. 1\% & 56.52 & 47.83 & 2.17 & 13.04 & 34.78 \\
\hline id. 2 (128) & 68 & 57 & 11 & 20 & 35 \\
\hline id. 2\% & 53.13 & 44.53 & 8.59 & 15.63 & 27.34 \\
\hline id. 3 (169) & 107 & 58 & 7 & 24 & 37 \\
\hline id. 3\% & 63.31 & 34.32 & 4.14 & 14.20 & 21.89 \\
\hline id. 4 (120) & 72 & 44 & 3 & 16 & 17 \\
\hline id. 4\% & 60.00 & 36.67 & 2.50 & 13.33 & 14.17 \\
\hline \hline
\end{tabular}

We dialogue with the concept of Stair and Reynolds (2018), arranging categorizations into Technical, Social, and Organizational. Initially, we thought that peripheral players would favor social improvement, but Table 11 shows that this premise has been refuted. All social groups pointed out, in greater quantity, technical improvement.

Answers could be framed in more than one category. For example, "improving the punishment system" was labeled as technical and social, as it involved system improvement and punishment. On the other hand, "punishing more" is just social. Some responses were labeled "irrelevant", as they explicitly deviated from the objective. For example, "delete Yasuo", which a player suggests excluding a disliked playable character from the game.

The occurrences of solutions associated with punishment were alarming. We structured a specific column for this information in Table 11. Since CES-D calculations did not reveal any significant variance, we omitted this information associated with these responses.

As in Carvalho et al. (2017), many respondents (16.23\%) explicitly assume that "punishing" or "improving punishment system" will improve the game. Moreover, less than five respondents indicated constructive, educational, or rewarding solutions. There were also few demands for greater graphic and explicit social diversity, e.g., non-thin bodies, non-stereotyped women, black characters, and others. However, there were several instances of "asymmetric punishment", as perceived in Section 5.3.

We were surprised by the number of respondents who pointed to punitive solutions. Players believe there is impunity in the company, since many of them feel that their reports of hate speech or negative behavior do not work. That brings us to another numerical discrepancy in categories: few players associate the system with the company (organizational aspect). Riot Games manages, controls, maintains and takes decisions about the game. Players focus on the system and the community, ignoring Riot Games' responsibility.

\section{5 "If you have suffered or observed a case of oppression or social discrimination in League of Legends, can you report it here?"}

This question is open and discursive. After treatment and normalization, we analyzed 264 valid responses. Table 12 shows the quantitative analysis of this issue.

Each testimony was coded and categorized according to a type of oppression addressed in this research. We complement the question by suggesting that respondents with expressively negative experiences do not give details, in order to avoid negative triggers. There was also an "I prefer not to respond" (PNR) answer. We obtained 293 types of negative interactions from 264 respondents. Some answers correspond to more than one category. For example, \#77: "That Northeasterners were starving trash and black people deserved to die." classified as "racism" and "xenophobia".

We inserted machismo and LGBTphobia, regardless of quantity, considering that the hypotheses of the quantitative analysis indicated statistical significance in the relationship between these oppressions and CES-D. We selected a $10 \%$ floor of 293 (29) to include other types, then we regarded racism (62) and PNR (58). All other types did not reach the floor, including neutral offenses. LGBTphobia had an insignificant number of occurrences (21), being disregarded from the quantitative analysis.

Considering CES-D values in Table 12, it makes sense for dominants to experience explicit oppression that does not affect their CES-D, including those directed at themselves and their friends. Despite the impressive reports of racism and machismo, the CES-D of these players had a minimal variance from dominants in general (15). However, dominants that preferred not to report presented worse CESD (17). The overall and peripherals analysis showed an aggravation of up to two points, associated with Machismo and PNR, reinforcing how these influences are negative.

Table 12: CES-D based on oppression report type

\begin{tabular}{||c|c|c|c|c|c|c||}
\cline { 2 - 8 } \multicolumn{1}{c|}{} & \multicolumn{2}{c|}{ All } & \multicolumn{2}{c|}{ Dominant } & \multicolumn{2}{c||}{ Peripheral } \\
\cline { 2 - 8 } \multicolumn{1}{c|}{} & Qty. & CES-D & Qty. & CES-D & Qty. & CES-D \\
\hline Racism & 62 & 17 & 23 & 14 & 39 & 18 \\
\hline Machismo & 86 & 18 & 15 & 14 & 71 & 19 \\
\hline PNR & 58 & 19 & 4 & 17 & 54 & 19 \\
\hline All & 293 & 18 & 56 & 16 & 208 & 18 \\
\hline
\end{tabular}

We did a specific analysis with oppressions and related identities, e.g., CES-D related effect on white (dominant) and non-white (peripheral) based on racism report. As expected, non-men and non-whites that reported oppressions associated with their identities showed an aggravation at CES-D. Regarding reported racism: whites, 16; and nonwhites, 19. Regarding reported machismo: men, 16; nonmen, 20. In a complementary way, we believe that if PNRs were reported, they would worsen this inequality. 
Qualitatively: oppressions lead players to cry; Women are oppressed even if their performance in-game is good, and men that play with or defend them are offended; Low game performance and specific nicknames are triggers for oppression, impressively, some cases dated back many years; Several players accommodated with the offenses and discrimination, all peripheral, "it's all right", "I'm used to it", "it's a reflection of how it is out of the game"; A female player was threatened with rape by a player who identified themself as fourteen years old; Streamers oppresses female players in real-time during a live broadcast. Lastly, a dominant player (\#501) reported "once a group with several gays started cursing me for having a hetero nickname and playing with a hetero champ", even though they explicitly said they did not consider this discrimination, illustrating the dichotomy of speech effects.

Again, there were reports of "asymmetric punishment", i.e., feeling of impunity, that Riot Games protects, ignores, or connives oppressors. On the bright side, some players, even if few, believe that their complaints worked; some players denounced oppressors even for cases not directed at them; some players defend each other; several dominants have some degree of awareness of the socially peripheral situation of their peers.

\section{Discussion}

In this Section, we discuss ethical issues, collusion with oppression, proposals for mitigation, and possible solutions.

\subsection{Is this topic ethically debatable?}

Some result elements of this research can be questioned ethically. The practice of oppression, per se, is morally abhorrent and unquestionably harmful to society. This Section grounds on the field of Computational Ethics (Barger, 2008; Johnson, 2008) and Cyberethics (Spinello, 2020), limited to the debate on social interactions from the perspective of an IS (Stair and Reynolds, 2018). We bring three approaches of ethical thought to debate this issue: Kantian categorical imperative, relativism, and utilitarianism.

Ideally, Riot Games handles cases of oppression by the categorical imperative. However, it generalizes to negative social interactions, that is, neutral offenses (e.g., asshole, sucker, twat, motherfucker, and others) and social oppressions (e.g., fagot, nigger, bitch, mental, daft cow, and others) are considered inappropriate conduct of the same magnitude. Also, reactions to oppression are assessed in the same way, as we noted in Section 5. So, if someone says: "You're a woman, you deserve to be raped", and they reply: "You're an asshole, don't say that", they both get punished. Does this mean that the oppressed have carte blanche to offend others? No, we will go into that in more depth in Section 6.2.

Nevertheless, the company cannot evaluate each case timely, considering the number of players. This generalization is made clear in Terms of Service, ${ }^{9}$ item 7 "User Rules", and sub-item 7.1 "Can I troll, flame, threaten or harass people while using the Riot Services? (No. If you do, we might take action such as banning your account.)". There is a list of behaviors that result in "disciplinary measures", item 5 wording says: "Transmitting or communicating any content which we reasonably believe to be offensive to players, including language that is unlawful, harmful, threatening, abusive, harassing, defamatory, vulgar, obscene, sexually explicit, or racially, ethically, or otherwise objectionable".

If the user's account promotes social oppression, as the text says, they are subject to disciplinary measures and even banning, at the discretion of Riot Games. It is Riot Games decision, through its algorithm or dedicated team, if (i) nothing will happen, (ii) a temporary punishment will be charged, or (iii) the account will be permanently banned. Through reports extracted from the questionnaire responses, observing communications in communities dedicated to $\mathrm{LoL}$ within the Internet, and through the literal interpretation of these mentioned terms, we realize that the ethical bias followed by the company is realistically relativistic.

Moral relativism dictates that all, or more than one, ethical points of view are valid. That is a plausible interpretation considering that Riot Games is a company that perpetuates oppressive social values (Carvalho et al., 2020). As an example, here is a statement from a company manager: "Diversity should not be a focal point of the design of Riot Games' products because gaming culture is the last remaining safe haven for white teen boys". In this way, it makes sense for action guidelines to assess social oppressions, that aim to annul rights and dignities of minorities, to be judged with the same weight as neutral, even banal, offenses.

Privately, a player sent a snippet of the response they obtained when reporting oppression ${ }^{10}$ :
"Pode confiar que vou dar o meu melhor olhando e cuidando do caso e vou me certificar de que as medidas cabíveis sejam tomadas nesse caso. Mas por questão de privacidade, não vou poder te falar a respeito do que pode acontecer com a conta de terceiros, por mais que eu entenda que a gente fique curioso. Eu também jogo, sabe? $A$ bastante tempo, na verdade... e desde que comecei a jogar, sei que muita gente diz que o report in game não ajuda em nada, que não adianta, e eu entendo perfeitamente isso. Mas ó, bota um pouquinho mais de fé

${ }^{9}$ https://www.riotgames.com/en/terms-of-service. Accessed: 01 January 2021.

10 "Trust me, I'll do my best looking for and taking care of the case. I'll make sure that the appropriate actions will be taken. But, for privacy reasons, I will not be able to tell you what can happen to third-party accounts, as much as I understand that we get curious. I play too, you know? For a while, actually... And, since I started playing, a lot of people say that in game reports doesn't help at all, that it doesn't work, and I perfectly understand that. But look, have a little faith in it, because it does help. Even though it's not $100 \%$ perfect. And of course, whenever you need it, the support team is here. So, remember that you're not alone. So, report it at the match's end. Even if you decide to send a ticket, ok?" (free translation) 
nele, porque ele ajuda sim, mesmo não sendo $100 \%$ perfeito. E claro, sempre que você precisar, tem aqui a equipe do suporte, então lembre-se de que você não está sozinho. Então reporta no final do jogo, mesmo que decida mandar um ticket, ok?"

From the discursive and open responses, we realize players are tired, disappointed, and frustrated with "trying to understand" that kind of report. Reports of impunity or feelings of impunity are proportionally much more frequent than reports of effective action. At the same time, it allows us to question: why do oppressive players "deserve privacy"? Why do those who oppress receive a guarantee of preservation and those who are oppressed remain with a sense of injustice?

Utilitarianly, the game already had a system called The Tribunal ${ }^{11}$ in which players would evaluate complaints and applied verdicts. It was established in 2011 and ended in 2014 , with no possibility of expected return.

The utilitarian bias presents two barriers: a specific and traditional. The specific barrier is anonymity. For example, assuming that a player is a target of racism, there is no way to guarantee that they are, outside the game universe, black. In this case, the onus is on the self-identification and subjectivity of the oppressed, moving away from the oppressive party's intent to deceit. A Latin player can be affected by racism. The issue complicates if we consider that this category of social oppression affects only black people. The traditional barrier is how utilitarianism operates by the motto: "an action is morally right if the consequences of that action are more favorable than unfavorable to everyone" (Fieser, 2020). Thus, as we have quantitatively observed in this research, the probability of women being harmed is exceedingly higher than men.

The morally correct action must also do everything possible to prevent suffering or pain for the disadvantaged. Since most players are not oppressed, it makes no difference to take decisions with potentially drastic consequences. However, the current scenario state exposes that mild decisions favor oppressors or result in soft permissive situations of unscrupulous moral self-negotiation. A player might say, e.g., "Even if I practice oppression, the maximum punishment I will receive is a warning, chat suspension, or temporary suspension in the game...". The routing option for this situation is straightforward, to purge the phenomenon through its promoters, and by direct consequence, to benefit those who are likely to suffer oppression. Promoting approaches through majority logic falls into utilitarian traps.

Three different scenarios are possible involving an oppression trigger: (i) player A tries to oppress player B, and player B responds to offending player A; (ii) player A tries to oppress player $\mathrm{B}$, and player $\mathrm{B}$ responds to trying to oppress player A; (iii) player A offends player B, and player B tries to oppress player A. Regardless of peripheral or dominant, the determination is annulled by anonymity, leaving only the inadmissible attempt to oppress. Despite the scenario, the tolerance for oppression must be nil, resulting in a permanent ban. Offenses should be subject to disciplinary measures, mild when reacting to oppression, harsh when spontaneous and disconnected.

Any objective attempt of oppression is unacceptable regardless of the speaker. Toxic or negative social interactions are subjectively apprehended by the recipients and they should be consulted in case third parties report. For example, as in mentioned scenarios, if player $\mathrm{C}$ feels overwhelmed by an attempt of undirected oppression, even though players A and B were absent from reporting, speech negatively affected the viewer. Even though A and B might have been joking with each other, if it caused discomfort in another player, then it was inappropriate anyway.

\subsection{Collusion with oppression}

In this Section, we address the scalability issue, i.e., how Riot Games deals with cases of oppression, regarding the applicable legislation.

A curious case (Gach, 2020) related to the COVID-19 pandemic started in 2020. A player changed his nickname to "Corona". The system flagged his nickname and asked him to change it. But previously, his nickname was "Squid Corona". The player was called Joao Corona, and, in Spanish, corona means crown. As a commentator points out, the game team preferred to neglect the player's subjectivity, linguistic specificity, and create an imbroglio of weeks to resolve (Gach, 2020). After almost a month of discussion with the game team, his nickname was whitelisted. Other offensive nicknames like "CoronaComin4U" and "ChinaVrs." were discussed.

This is an example of the scalability issue. How to deal with an extensive number of complaints and insufficient human resources, considering its complexity and time consumption? Complexity, as a case can be valid or not. A human task, as Riot Games cannot have such a large team dedicated exclusively to analyze complaints, and proportionately resolving them.

We stressed that scalability non-functional requirement associated with the reporting system is conniving oppression, considering that: (i) it is sickly, morally, and socially, to overlap the game's integral technical functioning with the recurrent oppression phenomena on the platform, as the company itself has registered more than this research exposes; (ii) it is possible to invest a profit amount to improve human resources capable of evaluating properly all reports, specifically for this purpose. Just as it is impossible to cover all complaints, it is impossible that Riot Games, with annual billionaire profits (Swan, 2020), is not able to hire human resources for this problem.

It is unknown how Riot Games, specifically in LoL, deals with player reports, which the company does not objectively disclose. What is known empirically? Reported players are not immediately banned, even for hate speech. When players reproduce oppression through players' nicknames, the company requires them to change them, even if it is hate speech, e.g., "Tranny Killer". Some players speculate about a "report score", and that specific fuzzy parameters make it

\footnotetext{
${ }^{11}$ https://leagueoflegends.fandom.com/wiki/The_Tribunal. Accessed: 01 January 2021
} 
increase or decrease. If players that reproduce social oppression remain active months after being explicitly reported, this assessment is quantitative. Thus, the "report score" is valid.

If we consider that there is a quantitative "report score", the next absurd step is asking: how many times should a player say (based on respondent \#390) "She lost the lane because she's a girl. Women's place is to do the dishes" 12 (free translation) to be punished? And if we consider that luck, and not an algorithm, leads a report to be evaluated by a human agent, is luck moral? (Fieser, 2020). Sending a print screen directly to the technical support, clearly exposing the oppression, is also not effective. The premises indicate a tolerance of Riot Games towards social oppression.

As some describe few days after reporting, the reported player was still active and playing. Thus, besides the oppressor is still in the game, there is also a probability to be matched with them. But if you ask for explanations, you will not receive them. Why? It is up to Riot Games to define disciplinary measures and punish players as it wishes, regardless of the psychosocial damage caused to you. The game is connected with the current national reality and applicable criminal laws.

In this research, most of the social oppressions denounced or reported by players, such as racism, sexism, and LGBTphobia, are punishable by law in Brazilian territory. ${ }^{13}$ Any terms the game might present are not above the law, i.e., it is not exclusively up to Riot Games in its terms of service, as discussed in Section 6.1, to define "disciplinary measures". If Riot Games evaluates any case without a "zero tolerance" principle, as we expose, it indicates connivance and consents to the permanence of this oppressive player in its network, assisting social oppression.

In Brazil, there are police stations specialized in virtual crimes, ${ }^{13}$ such as oppression carried out in the cyberspace sphere. Players have the right to denounce and monitor the report, even digital games ones. This scenario is simplified considering that the BR server is dedicated to Brazil, so the spatial scope remains national.

Analyzing answers to the three discursive and open questions, we perceive a frequent scenario of apathy, consent, or inaction. One of the unpleasant findings of this survey is that while players expect Riot Games to punish oppressors "harder", they forget that hate speech is a crime, inside or outside the game. If anonymity is problematic, if Riot Games is exempt from the responsibility of communication in its games, if the investigation and the process will be arduous, none of this is a hindrance for the player, as a person and citizen, to assert the rights and duties involving the society in which it participates.

\subsection{Thinking about solutions and mitigation}

Technically, it is necessary to dissociate the phenomenon and the game. Riot Games is indirectly responsible for actions within the scope of its system. In this sense, we believe that Riot Games can provide a gaming environment that is anti-oppressive and also combats social oppression. If it is up to us to list a villain or these problems root, it would be unfair to address the entire burden to Riot Games. Also, people that compose Riot Games collectivized represent the agent with the greatest influence in this ecosystem. As the game owner, it has more power and privilege to promote a positive impact.

In this Section, we dialogue with the Ethics of Resistance perspectives (Christians, 2007; Samuel, 2013; Klikauer, 2014; Alakavuklar e Alamgir, 2018) to think about the next steps. We see Riot Games as an ally against the phenomenon of social oppression, aware of how the power and social privilege external to the game go through it and are present internally and externally. We analyzed the questionnaire responses, as it is the respondents' and LoL players' voices. We summarize the implicit and explicit referrals structured below. We aim to build an atmosphere that is positive and inclusive and, at the same time, intolerant for oppression, injustice, social inequality, and exclusion.

The scope of this Section is to provide insights on the improvement of healthy social interactions. Therefore, the objective is to propose possible alternatives, direct or indirect, for solutions and mitigation to problems exposed in this research through social interactions that harm the players' mental health.

From the questionnaire responses, we extracted some proposals. As well as the already well-established rank ("Elo") mechanism associated with playing skill, all players would have a social rank or moral rank. Players would be paired with others of the same, or close, rank. As a negative aspect, this proposal encourages ostracism; as a positive aspect, it allows everyone to keep playing and only associating close social profiles. Neutral players remain close to zero, like those who exempt themselves from communication by their own choice; and socially active players vary in either positive or negative. Players that remain on the positive spectrum will have access to additional features, such as the blue essence shop, and rewards, rewarding players not only for their skill or technique performance during matches but also for the social assessment of their match mates.

Creating a partnership system between veterans and newbies, rewarding both for playing together and sustaining a learning bond. Social interactions can be very harmful to novice players, who, when accompanied, can resist these scenarios better. This ratio presents a trick widely criticized by the community: veteran players that create accounts to play with newcomers and take advantage of their inexperience. It is up to the system and its game quality standard recognition algorithms, then, to validate if the pair is composed, in fact, by a veteran and a novice.

Creating a new game mode: collective training. Many complaints of oppression or offense come from players trying to learn and being a target of toxicity from others. Two of the most famous modes are "Normal" and "Ranked". Many players choose the Normal mode to test new

\footnotetext{
12 "Perdeu a lane porque é menina, lugar de mulher é lavando a louça".

${ }^{13}$ https://new.safernet.org.br/content/delegacias-cibercrimes. Accessed: 01 January 2021.
} 
champions and not necessarily win, while others resort to this mode to escape Ranked mode and, competitively, try to win. The collective training mode would be open to everyone, with the premise of testing and training, while the Normal mode would be restricted to champions with a player's reasonable mastery score.

To increase the number of human agents involved in the analysis and evaluation of reports, with less generic and socially critical criteria, considering the socially unequal reality external to the game.

To promote categorically engaged and targeted campaigns. For example, to bring Riot Games LGBTQ+, women, and black employees to engage players and demonstrate a concrete concern with diversity.

To allow players to follow up on their complaints in case of negative or toxic social interactions, setting out the conclusion and justifying the verdict. Also, if possible, to encourage reconciliation and exchange of ideas. Often players "let themselves be carried away by the moment" and do not think about the consequences of their actions. Encouraging (but not dictating) dialogue allows both parties to a common ground about feelings and affections.

Concretely, the Ethics of Resistance despises illusions of false principles, values, and traditionalisms. For this same reason, no solution involves "educating" or "humanizing" oppressors, because this is not and should not be directly the goal of a digital game like LoL. Indirectly, this objective should be primary for if the game enables social phenomena like this in its functionalities, there is a co-responsibility from the service administration. If the games did not present text or voice chat for everyone, and no option to enable them, the phenomenon would be radically mitigated. Otherwise, communication would be impaired.

If Riot Games do not implement a concrete, objective, and constructive attempt to improve social interactions, the recommendation is that players boycott the game and look for similar ones. Indeed, there are many available. The belonging intention is a strong emotional motivation, and it is rationally harmful to remain in a virtual environment where the entity, with the power and privilege to promote socially positive changes, neglects non-dominants.

\section{Conclusion}

Collecting data through an online questionnaire, we associate social oppressions, phenomena, and behaviors of the League of Legends game with depressive disorder and social identities, from a scheme of social hierarchy. We adopt a quantitative psychometric analysis, using a CES-D approach and a mixed/qualitative textual analysis. We reiterate Rebhein's intersectional perception (2018), which claims that identity elements produce and reproduce power structures. In this work, we consider gender/sex, sexual orientation, skin color, and region of origin as some of these elements. Through the Social Dominance Theory (Sidanius and Pratto, 1999), we emphasize the need to analyze the reproduction of inequity through the interaction of different power dimensions.
The research revolves around eight hypotheses, four of which were correlated hypotheses related to the first hypothesis, associating depressive disorder symptoms with specific social groups. We conclude that, in a broader sense, LoL and its social interactions are more harmful to peripherals when compared to dominants. The more distant from social dominance the identity is, the more susceptible it is to worse depressive symptoms. Playing time and oppression perception have a worse impact on peripherals when compared to dominant ones. Muting is not significantly influential to psychosocial inequality, despite the specifically negative results associated with muting all other players in the match.

Mixed/qualitative analysis complements the research and deepens the phenomenon exposed by the hypotheses, showing how they occur. From coding and categorization, we perceived common occurrences and, after analyzing them one by one, we highlight the most impressive ones. Most players view social interactions in the game as negative, and some have positive experiences only playing with friends. The suggestion of punishment is prevalent in the players' perception of game improvement. Machismo and racism are the most reported oppressions, and even though racism was not considered statistically significant in the quantitative analysis, this qualitative view underscored how harmful this type of oppression is.

Players that identify as non-masculine and nonheterosexual present significantly worsening mental health when compared to males and heterosexuals. Skin color and region of origin were not significantly influential in this analysis, still, their CES-D values are relatively worse.

If a social group perceives oppression, even only one category of it, there is a significant negative impact on the CES-D result, aggravating as more categories of oppression are perceived. As expected, players that did not perceive or do not perceive oppression present relatively positive and healthy results in the CES-D.

Finally, we ethically discussed the research's scenario and the way that Riot Games deals with the issue, emphasizing how unacceptable and morally abhorrent the practice of social oppression is. Then, we reflect on possible interpretations of connivance with oppression, clarifying that regardless of the speaker, dominant or peripheral, there should be no tolerance for social oppression. We concluded by pointing out possible ways to mitigate or solve the problems explained by this research, bringing proposals from the questionnaire's answers. We believe that the phenomenon of oppression has no single culprit. In this network, Riot Games is the agent with more power and privilege, symbolic or concrete, to make exemplary decisions.

Concerning reproducibility and generalization, the research can be reproduced for different games with social interaction, or still considering LoL, repeat the method on other servers, or even consider another time parameter. Generalizations are restricted to the Brazilian context and the temporality of this research, as it has a sociocultural bias. The findings and contributions of this research can be transferred, through punctual evaluation, to multiplayer, 
online games that enable social interaction by voice or text chat and have report functionality, e.g., Riot Games' Valorant. Although being a different style (First Person Shooter), it fits the specific criteria.

We list as research limitations: (i) a small number of id.1 and id.0 respondents, which was a challenge to raise; (ii) closed scope in the Brazilian reality, on the BR server; (iii) the impossibility of doing a quantitative association between the number of BR server players (Brazilian population that plays LoL) with the research sample, considering that Riot Games does not disclose this data.

Possible future work includes further analyses of the data presented, from other groups of identities, and multivariate analyses; conducting other questionnaires to collect more data; an in-depth and qualitative study of totally peripheral social identities (id.0) with emphasis on their specific experiences in LoL.

\section{Acknowledgments}

This study was funded by the Coordination for the Improvement of Higher Education Personnel - Brazil (CAPES) - Financial Code 001.

This is an extended version of the paper "League of Legends e Saúde Mental, uma Perspectiva Social Brasileira" published on the Health Track at the XIX Brazilian Symposium on Games and Digital Entertainment. Awarded as the Health Track best article.

\section{References}

Adams, E., (2014). Fundamentals of Game Design. New Riders Publishing.

Agresti, A., Franklin, C., Klingenberg, B. (2017). Statistics, The Art and Science of Learning from Data. ed. 4. Pearson.

Alakavuklar, O. N., Alamgir, F. (2018). Ethics of Resistance in Organisations: A Conceptual Proposal. J Bus Ethics. 149:31-43.

Almeida, B. O., et al. (2019). Violência de Gênero nos Jogos $O$ papel da indústria dos jogos na banalização da violência contra a mulher. SBGames'19. pp. 826-834. Rio de Janeiro. Rio de Janeiro.

American Psychiatric Association (2014). DSM-5: Manual diagnóstico e estatístico de transtornos mentais. Artmed.

Araújo, G., (2019). Jogo é coisa de menino: a discriminação em League of Legends. Semiótica da diversidade: devires minoritários e linhas de fuga. Editora Fi. pp. 215228. Porto Alegre.

Barger, R. (2008). Computer Ethics: A Case-Based Approach. Cambridge University Press.

Benuto, L., Duckworth, M., Masuda, A., O'Donohue, W. (2020). Prejudice, Stigma, Privilege, and Oppression, A Behavioral Health Handbook. Springer.

Bhattacherjee, A. (2012). Social Science Research: Principles, Methods, and Practices. ed.2. Textbooks Collection.
Bogost, I., (2007). Persuasive Games, The Expressive Power of Videogames. ed. 1. The MIT Press. USA.

Boscagli, M. (2014). Stuff Theory: Everyday Objects, Radical Materialism. Bloomsbury Academic.

Butler, J., (2004). Undoing Gender. Routledge.

Carvalho, E., Rocha, G. (2018). Categorização dos Termos Utilizados em Episódios de Cyberbullying no Jogo League of Legends. Revista Tuiuti. 4(53).

Carvalho, L. P., Cappelli, C., Pimentel, M. (2018). Sexismo e League of Legends: Comunidade Externa e Interna. ABCiber'18. Minas Gerais. Juiz de Fora.

Carvalho, L. P., Oliveira, J. (2020). Subjectivities in Software Development from an STS and Social Institution Perspective, a Riot Games Case Study. WASHES'20. Cuiabá, Mato Grosso.

Christians, C. G. (2007). Neutral Science and the Ethics of Resistance. In: Denzin, N. K., Giardina, M. D. (eds) Ethical Futures in Qualitative Research. Routledge.

David, E., Derthick, A. (2017). The Psychology of Oppression. Springer Publishing Company.

De Choudhury, M., Counts, S., Horvitz, E. (2013). Social Media As a Measurement Tool of Depression in Populations. Proceedings of the 5th Annual ACM Web Science Conference. pp. :47-56.

Del Porto, J. A., (1999). Conceito e diagnóstico. Rev. Bras. Psiquiatr. 21(1):06-11.

Denzer, TJ., (2020). Shocking percent of League of Legends players claim they've never been harassed. SHACKNEWS. Accessed: 01 January 2021, at: https://cutt.ly/vgkLQyr

Diener, E., Crandall, R. (1978). Ethics in social and behavioral research. Chicago Press.

Eyal, N., (2014). Hooked: How to Build Habit-Forming Products. Portfolio.

Ferreira, E. R., Pimentel, C., Melo, P. (2020). O Perfil Consumidor em Jogos Free-to-Play: Os Fatores de Influência na Decisão de Compra dos Jogadores em League of Legends. SBGames'20. pp. 876-885. Recife, Pernambuco.

Fieser, J. (2020). Ethics. In The Internet encyclopedia of philosophy. Accessed: 01 January 2021, at: https://iep.utm.edu/ethics/

Flores, J., Real, L. (2018). Jogos online em grupo (MOBAS): Jogadores Tóxicos. SBGames'18. pp. 956959. Paraná. Foz do Iguaçu.

Fox, J., Tang, W. T. (2014). Sexism in online video games: The role of conformity to masculine norms and social dominance orientation. Computers in Human Behavior. 33:314-320.

Gideon, L., (2012). Handbook of Survey Methodology for the Social Sciences. Springer.

Goslin, A. (2019). League of Legends has nearly 8 million peak daily concurrent players globally. Rift Herald. Accessed: 01 January 2021, at: https://cutt.ly/sgkLspo

Grace, V., (2012). Victims, gender, and jouissance. Taylor \& Francis. 
Hanna, F. J., Talley, W. B., Guindon, M. H. (2000). The power of perception: Toward a model of cultural oppression and liberation. Journal of Counseling and Development. 78:430-446.

Hutz, C. S., Bandeira, D. R., Trentini, C. M. (2015). Psicometria. Artmed.

IGN (2012). Riot Games Releases Awesome League of Legends Infographic. Accessed: 01 January 2021, at: https://cutt.ly/4gkLYUg

Johnson, T., (2015). Handbook of health survey methods. John Wiley \& Sons.

Jonhson, D. (2008). Computer Ethics. ed. 4. Pearson.

Klikauer, T. (2014). Social Justice and the Ethics of Resistance: A Review Essay. Soc Just Res. 27:518-525.

Locke, L. A., (2019). Typical Areas of Confusion for Students New to Qualitative Research. In: Strunk, K., Locke, L. (eds) Research Methods for Social Justice and Equity in Education. Palgrave Macmillan.

Marchetti, B., (2017). China Has a Massive League of Legends Player Base. DBLTAP. Accessed: 01 January 2021, at: https://cutt.ly/pgkLvxs

Medrado, A., Mendes, A. (2020). O silêncio não é a melhor arma: misoginia e violência contra as mulheres no game league of legends. Revista Interamericana de Comunicação Midiática. 19(39):143-165.

Merriam, S., Tisdell, E. (2015). Qualitative research: A guide to design and implementation. John Wiley \& Sons.

Radlof, L. S., (1977). The CES-D Scale: A self-report depressive scale for research in the general population. Journal of Applied Psychological Measurement. 1:385401.

Ratan, R. A., Taylor, N., Hogan, J., Kennedy, T., Williams, D. (2015). Stand by Your Man: An Examination of Gender Disparity in League of Legends. Games and Culture. 10(5):438-462.

Recker, J. (2013). Scientific Research in Information Systems, A Beginner's Guide. Springer.
Rehbein, B., (2018). Social Classes, Habitus and Sociocultures in South Africa. Transcience. 9(1):1-19.

Rogers, S., (2013). Level Up! the Guide to Great Video Game Design. ed. 2. John Wiley \& Sons

Rosenquist, J. N., Fowler, J. H., Christakis, N. A. (2011). Social network determinants of depression. Molecular Psy. 16(3):273-281.

Samuel, C. (2013). Symbolic Violence and Collective Identity: Pierre Bourdieu and the Ethics of Resistance. Social Movement Studies. 12(4):397-413

Schulman, S. (2016). Conflict Is Not Abuse: Overstating Harm, Community Responsibility, and the Duty of Repair. Arsenal Pulp Press.

Sidanius, J., Pratto, F. (1999). Social dominance: An intergroup theory of social hierarchy and oppression. Cambridge University Press.

Spinello, R. (2006). Cyberethics: Morality and Law in Cyberspace: Morality and Law in Cyberspace. ed. 7. Jones \& Bartlett Learning.

Stair, R. M., Reynolds., G. W. (2018). Principles of Information Systems. ed. 13. CENGAGE Learning.

Stetina, B., Kothgassner, O. D., Lehenbauer, M., KryspinExner, I. (2011). Beyond the fascination of onlinegames: Probing addictive behavior and depression in the world of online-gaming. Comput. Hum. Behav. 27(1):473-479.

Wasserstein, R., Schirm, A., Lazar, N. (2019). Moving to a World Beyond " $\mathrm{p}<0.05$ ". The American Statistician. 73:1-19.

Wei, H., Chen, M., Huang, P., Bai, Y. (2012). The association between online gaming, social phobia and depression: an internet survey. BMC Psychiatry. 12(92).

Çakir, G. (2020). How to Mute Players in League of Legends. Dot Esports. Accessed: 01 January 2021, at: https://dotesports.com/league-of-legends/news/how-tomute-players-in-league-of-legends 